\title{
SOBRE LOS MOMENTOS INICIAL Y FINAL DE LA TENTATIVA
}

\author{
Antoni Gili Pascual*
}

Resumen**: Este trabajo se ocupa de dos cuestiones que atañen a sendos límites, inferior y superior, de la tentativa. En relación con el primero, se analiza como cuestión específica el inicio de ejecución en las tentativas acabadas, examinando para ello los posicionamientos que han defendido el establecimiento en estos supuestos de un criterio propio y distinto del utilizado para las tentativas inacabadas. En el segundo ámbito, el trabajo concreta el concepto de tentativa terminada y clarifica qué pertenece en realidad al mismo intento punible, precisando de este modo hasta cuándo se puede desistir válidamente de él. Las aportaciones contenidas en el estudio interesan, pues, tanto a la habilitación o apertura de la posibilidad de desistir como a su preclusión o cierre.

Palabras clave: Inicio de ejecución en la tentativa, tentativa terminada.

Recibido: febrero 2021. Aceptado: julio 2021

* Profesor Titular de Derecho Penal. Universitat de les Illes Balears. Facultad de Derecho. Edf. Gaspar M. de Jovellanos, Ctra. de Valldemossa, km 7’5, 07122-Palma. E-mail: antoni.gili@uib.es

** Estudio realizado en el marco del proyecto DER2017-86336-R (AEI/ FEDER, UE). 


\begin{abstract}
This article investigates two issues that affect the lower and upper boundaries of the crime of attempt. In terms of the former, the commencement of execution in completed attempts is analysed as a specific issue, examining positions that have defended using different inherent criteria than for incomplete attempts. With regard to the upper boundary, the article specifies the concept of complete attempt and clarifies what actually applies to punishable intent, thus setting out up to what point one can validly desist from enacting said fact. The contributions of the study are of interest both for enabling or opening up the possibility of desistance and for its preclusion or closure.
\end{abstract}

Keywords: Commencement of execution in attempt; completed attempt.

\title{
I. Tentativa acabada e inicio de ejecución
}

\section{Planteamiento}

La concreción del momento o circunstancias a partir de las que debe considerarse iniciada la ejecución del delito o -en lo que se supone comúnmente lo mismo ${ }^{1}$ - la fijación de la frontera entre los actos preparatorios individuales y lo penalmente relevante, constituye sin duda uno de los problemas nucleares de la teoría del delito intentado. En este terreno el grueso de los esfuerzos doctrinales se ha concentrado habitualmente en torno a la tentativa inacabada, considerándose

1 Aunque no necesariamente lo es, pues en la identificación entre actos ejecutivos y responsabilidad por tentativa reside el germen de algunas confusiones en la materia. En este sentido, debe prevenirse desde el primer instante sobre la parte de responsabilidad que puede corresponder en ello a la cuestión terminológica. Los comportamientos ejecutivos en sentido naturalístico (acciones u omisiones encaminadas a la consecución del resultado), aun si concluidas, pueden no constituir tentativas en sentido valorativo, dependiendo del planteamiento doctrinal acogido. Doctrinalmente se ha propuesto, de hecho, hablar de "ejecuciones acabadas" para no prejuzgar su carácter de tentativa en términos penales (ALCÁCER GUIRAO, R., Tentativa y formas de autoría. Sobre el comienzo de la realización típica, Ed. Edisofer, Madrid, 2001, p. 119). 
incluso un problema ficticio o meramente aparente siquiera su planteamiento en relación con la tentativa acabada.

El argumento que sostiene esta última convicción descansa en la suposición de que si la tentativa ha llegado tan lejos como para considerarse acabada sería descabellado plantearse siquiera que pudiera ser un mero acto preparatorio. Pero esta afirmación, en virtud de la cual se viene a considerar absurdo preguntarse si se ha iniciado o no algo que está ya tan avanzado que permite considerarlo "acabado", se asienta, por un lado, en una confusión conceptual -y terminológica- entre ejecución y tentativa, con la que se procede a identificar el plano naturalístico (el agente no va a "ejecutar" más actos) con el valorativo (pero tal vez con ello no concurre aún el desvalor necesario de la tentativa $)^{2}$; por otro lado, descansa en una ficción, la de la linealidad del iter criminis (que estaría así supuestamente integrado por una secuencia unidireccional en la que la llegada a la siguiente etapa presupone necesariamente el paso por todas las anteriores), que no se corresponde exactamente con la realidad: existen tentativas acabadas a las que cronológicamente no precede una tentativa inacabada, sino un acto preparatorio impune, al igual que existen tentativas inacabadas a las que no sucede su modalidad acabada, sino la consumación (estructuras de consumación anticipada). Pero no es esto lo que ahora nos ha de interesar. Sino subrayar que el argumento a fortiori antes apuntado no permite resolver de un plumazo, por la vía de menospreciar el problema, la cuestión relativa a cuántos criterios sobre el "inicio de ejecución" (léase afloramiento de la tentativa) deben emplearse. Ciertamente, este trabajo se inclina hacia la consolidación de un criterio unitario

2 Naturalmente, si la afirmación se sostiene en el mismo plano-el, por así denominarlo, naturalístico- resulta absurda: ¿cómo preguntarse, en la misma dimensión, si empezó o no lo que ya está acabado o acabando? El problema reside en que esa observación, que es cierta, se obtiene en lo fenomenológico, pero se aplica o traslada acríticamente a lo valorativo. 
en virtud del cual transitar de lo permitido a lo prohibido en el ámbito de lo intentado, entre otras razones porque no se comparte, con carácter general, la idea de que puedan extraerse auténticos rendimientos dogmáticos, más allá de los puramente descriptivos, de la distinción entre tentativas inacabadas y acabadas, de modo que el inicio de ejecución no ha de partir de -ni venir determinado por- la previa catalogación del supuesto como tentativa acabada o tentativa inacabada conforme a los criterios al uso. Pero no puede ignorarse que existen, de hecho, sólidas y fundadas propuestas doctrinales que defienden la utilización de criterios distintos para el inicio de la ejecución en la tentativa inacabada y en la acabada, y este ha de ser ahora el motivo de atención: si, en caso de que en efecto proceda una diversificación de los criterios, debe concederse a esa división tradicional de los intentos algún papel determinante.

\section{La posición diferenciadora}

En el ámbito germano, el punto de inflexión para la activación de este debate específico en torno a un posible inicio de ejecución propio y diferenciado en la tentativa acabada puede situarse, como señala Alcácer ${ }^{3}$, en los años setenta ${ }^{4}$. De la mano de determinados ejemplos académicos (en realidad autorías mediatas con resultado diferido en el tiempo -estructuralmente tentativas acabadas- en las que coincide en el instrumento la condición de víctima), se venía a poner entonces de manifiesto la falta de inmediatez que podía experimentarse - pese a haber llevado ya a cabo el autor todo lo necesario para consumar el delito- tanto en relación con la realización propiamente típica como con el peligro para el bien jurídico. Se trataría de supuestos del tipo "A envenena el producto que consumirá la víctima al regresar a casa", que

3 ALCÁCER GUIRAO, R., Tentativa y formas de autoría ..., cit., p. 115.

4 Véase, ROXIN, C., Der Anfang des beendeten Versuchs, en Festschrift für R. Maurach zum 70. Geburtstag, Müller Verlag, 1972, p. 213 ss. 
motivaron propuestas tendentes a retrasar la barrera de la punición en tales casos, particularmente en el ámbito de la autoría mediata, pero también, por extensión, en las tentativas acabadas, estructuralmente coincidentes.

La proximidad que en diversos sentidos demanda el término utilizado en la definición alemana de la tentativa ("unmittelbar"), con la que se considera intentado el delito solo cuando el agente, según su representación del hecho, se dispone inmediatamente a la realización del tipo ( $\$ 22 \mathrm{StGB})$, está a mi entender detrás de los esfuerzos suplementarios efectuados para ubicar de forma más respetuosa con el principio de lesividad la ejecución imperfecta cuando se advierte una lejanía espacio-temporal llamativa con el resultado. En esto, el derecho español usa un adverbio que resulta en aquel sentido menos inquietante o comprometedor ("directamente"), pero también es verdad que, a cambio, la propia literalidad del art. $16 \mathrm{CP}$ podría impulsar incluso en mayor medida que en el derecho alemán la búsqueda de un criterio diferenciado para cada dosis de ejecución, pues tendría apoyo directo en la letra de la ley entender que hay un inicio específico para quien da principio a la ejecución practicando "todos" los actos que objetivamente deberían producir el resultado, como indudablemente debe haberlo para quien practica solo "parte" de aquéllos. Pero, sea cual sea la fuerza que quepa atribuir al tenor legal para animar a zambullirse en esta cuestión, lo cierto es que también en la doctrina española, siguiendo en esto la estela de las reflexiones germanas, se ha sostenido un inicio distinto para cada clase de tentativa.

En el caso de la tentativa inacabada, Alcácer ha sostenido - coincidiendo hasta aquí con la doctrina dominante ${ }^{5}$ la teoría de los actos intermedios (Zwischenaktstheorie),

5 Puede verse, GIMBERNAT ORDEIG, E., Autor y cómplice en Derecho penal. Universidad de Madrid. Facultad de Derecho. Sección de Publicaciones e Intercambio, 1966, p. 106; MIR PUIG, S., PG 13/58; o FARRÉ TREPAT, E., La tentativa de delito, 1986, p. 228 ss. (2 $2^{\mathrm{a}}$ ed., p. 275 ss.), quien se refiere a la teoría de la inmediatez de los actos. 
aderezada con la exigencia de un "peligro considerable para el bien jurídico, a determinar desde una perspectiva objetiva ex ante", y sin prescindir en todo ello del plan del autor ${ }^{6}$. Esto significa que para tener por iniciado penalmente el intento habrá que requerir que no falten ya actos intermedios entre la acción realizada y la propiamente típica, amén de un peligro de entidad suficiente para el objeto de protección. Para la tentativa acabada, en cambio, sirviéndose de los criterios (más elaborados) utilizados por la doctrina para precisar el inicio de ejecución en la autoría mediata, y apoyándose para ello en la identidad estructural que emparenta a ambos conceptos $^{7}$, sostiene una variación de la solución formulada en Alemania por Roxin (que a su vez podría ser considerada una variante de la solución del autor mediato o solución individual -Einzellösung-) $)^{8}$. En concreto, estima que la tentativa en la ejecución acabada comenzará solo con el abandono del control sobre el riesgo, "abandono que podrá ser activo, a partir de la realización de actos encaminados a la decisión del autor de dejar que el peligro siga su curso - por ejemplo, abandonar el lugar de los hechos--, o pasivo, permitiendo que el peligro llegue a la situación crítica en la que ya no podrá controlarse con un grado razonable de seguridad la decisión sobre el acaecimiento del resultado" 9. Dicho abandono,

6 AlCÁCER GUIRAO, R., Tentativa y formas de autoría ..., cit., p. 29 ss., 69 ss.

7 Cabe recordar que la autoría mediata no es, en este sentido, sino una modalidad de tentativa acabada, con la particularidad de que en ella interviene un instrumento humano -que puede ser o no coincidente con la víctima- mientras que en la tentativa acabada lo que conducirá al resultado será un elemento no humano -un suceso natural, un animal, un riesgo distinto del creado por el autor pero del que el autor se aprovecha, etc.-

8 Por contraposición a la solución del instrumento o solución global Gesamtlösung-, que consideraría como un todo la actuación de autor mediato e instrumento para pasar a situar en la intervención de este último el inicio de ejecución.

9 ALCÁCER GUIRAO, R., Tentativa y formas de autoría ..., cit., p. 138 ss. y 206 ss. 
conviene precisarlo, tiene en el planteamiento de Alcácer un cariz marcadamente subjetivo, aunque formalmente se sostiene un criterio mixto subjetivo-objetivo (que partiría del plan del autor pero enjuiciado éste desde un punto de vista objetivo $^{10}$ ): lo determinante, a fin de cuentas, será que el autor decida abandonar el riesgo ${ }^{11}$.

Para completar esta rápida panorámica sobre la postura de referencia, interesa comentar también, brevemente, dos cuestiones.

Primero, recalcar que tal planteamiento se hace extensivo a otras construcciones que comparten la estructura de la tentativa acabada (no solo a la autoría mediata), como es el caso de la comisión por omisión. En esta última, respecto de la que se viene a admitir la viabilidad de la distinción -a diferencia de otras posturas que la niegan o bien le niegan utilidad alguna-, se considerará, coherentemente con lo anteriormente expuesto con carácter general, que la fase ilícita

10 ALCÁCER GUIRAO, R., Tentativa y formas de autoría ..., cit., p. 184 ss. El autor descarta tanto un criterio estrictamente subjetivo, centrado en la representación del autor, como exclusivamente objetivo, que pondría el acento en la pérdida real y objetiva del control. Por su parte, el criterio mixto acogido (subjetivo-objetivo) es preferido frente a la combinación mixta inversa (objetivo-subjetiva) -que daría mayor relevancia a la pérdida objetiva del control en lugar de dársela al abandono subjetivo- argumentando fundamentalmente que tal concepción objetivo-subjetiva resulta incompatible con el desistimiento en la medida en que "la solución de una pérdida real y efectiva llevaría a la absurda conclusión de que siempre que se hubiera desistido no habría comenzado la tentativa, puesto que el mero hecho del desistimiento efectivo demostraría que el control definitivo sobre el riesgo no se habría perdido". Se impondría, en suma, el criterio subjetivo-objetivo señalado.

11 ALCÁCER GUIRAO, R., Tentativa y formas de autoría ..., cit., p. 187. De modo que -se indica-si el autor deja activado el dispositivo explosivo decidido a no volver habrá tentativa, aunque la víctima no vaya a regresar en dos semanas. En cambio, no la habrá aún si el autor se va a comer algo pensando en volver. El "grado de confianza" en el retorno de la víctima se convierte así en lo decisivo, pues "determinará la presencia de una tentativa o la inexistencia de la misma en el momento en que el autor se va" (ALCÁCER GUIRAO, R., op. cit., p. 190). 
comenzará únicamente cuando el sujeto abandone -o pierda voluntariamente- el control debido de un foco de peligro ${ }^{12}$, dependiendo aquí la caracterización de la fase imperfecta como inacabada o acabada del grado de seguridad (de la dificultad, en suma) en las posibilidades de recuperar el control del peligro una vez comenzada la tentativa ${ }^{13}$. Se considerará inacabada la tentativa, así, cuando el autor haya abandonado ese control del foco de riesgo pero sin haberlo perdido objetivamente, de modo que pueda retomarlo con seguridad, sin necesidad de tener que adoptar medidas extraordinarias de salvación. Será, en cambio, acabada, en caso contrario, es decir, cuando el autor haya perdido objetivamente dicho control, de modo que para retomarlo de forma segura y evitar el resultado requiera de medidas "extraordinarias y urgentes realizadas in extremis"14.

En segundo lugar, debe prestarse atención al hecho de que la inclusión de la decisión del autor de abandonar el control del riesgo en la conformación del inicio de ejecución (y no solo la toma en consideración para ello de la realización de los actos objetivamente encaminados a ese fin), conlleva el consiguiente retraso del momento en que adquirirá relevancia penal el comportamiento (que pasará del último acto ejecutado por el autor hasta aquel en que, en la fase omisiva de la actuación en su conjunto, pierda dolosamente dicho control), y ello habrá de tener su incidencia, a su vez, en la conformación de la responsabilidad subsiguiente, en caso de que finalmente sobrevenga la producción del resultado.

En efecto, el juego de los criterios que deben regir la imputación, en particular la exigencia de un dolo actual sobre el comienzo de la acción típica y el principio de

12 ALCÁCER GUIRAO, R., "Comienzo de la tentativa en la comisión por omisión”, $C P C, \mathrm{n}^{\circ} 73,2001$, p. 24 ss.

13 ALCÁCER GUIRAO, R., "Tentativa y desistimiento en la comisión por omisión”, La Ley, n 5, 2002, p. 1460.

14 ALCÁCER GUIRAO, R., “Tentativa y desistimiento ...”, cit., p. 1461. 
coincidencia (entre el tipo objetivo y el tipo subjetivo), arrojan con aquel presupuesto de partida algunos desajustes que no pueden ser ignorados, impidiendo una automática afirmación de la imputación al dolo del resultado. Así, se dirá en primer lugar, en los casos en los que el sujeto pierde involuntariamente el control sobre el peligro (recuérdese, dolosamente generado), produciéndose el resultado (p. e., si el sujeto que ha dejado envenenado el café molido de su víctima confiando que ésta regresará a su domicilio dos días más tarde, sale a comer algo con intención de volver y es atropellado -lo que le impide regresar, falleciendo la víctima $-{ }^{15}$ ), resultará apreciable únicamente un delito imprudente -a diferencia de lo que habría que sostener respecto de la estructura homóloga de consumación anticipada en el ámbito de la tentativa inacabada (=tentativa+delito imprudente)-, justamente por no existir un comienzo de tentativa en nuestro caso.

Por otra parte, se efectúa una matización relevante también en los casos de abandono doloso del control ${ }^{16}$, que asimismo tendrá su incidencia en el tratamiento de los supuestos en los que acaba produciéndose el resultado. Se distingue aquí entre un abandono doloso del control del peligro pero no acompañado de una pérdida objetiva del mismo (p.ej., una vez activado el explosivo conectado al interruptor que accionará la víctima, el autor abandona el domicilio, pero conservando la llave que le permitirá regresar sin dificultad), y un abandono doloso sí acompañado de la pérdida objetiva de aquel control, que requeriría ya de medidas extraordinarias -de más dificultosa ejecución- para la salvación del bien jurídico. El primer caso será considerado una "tentativa acabada incompleta", cuyo tratamiento habría de traducirse en un concurso entre la tentativa y el delito de resultado imprudente. Solo el segundo, en este sentido,

15 ALCÁCER GUIRAO, R., Tentativa y formas de autoría ..., cit., p. 191.

16 Análoga a la expuesta para diferenciar entre la tentativa inacabada y la tentativa acabada en la comisión por omisión. 
conllevaría la apreciación del delito consumado, aplicando la atenuante análoga a la de reparación si el sujeto intentase después revertir la situación infructuosamente, en tanto que desistimiento malogrado.

\section{Revisión}

Pues bien, una vez expuestas las grandes líneas de esta concreta doctrina diferenciadora, cabe preguntarse si las categorías tradicionales de tentativa inacabada/tentativa acabada deben ejercer realmente en esta cuestión algún papel decisorio, o sería de algún modo obligado pasar por ellas. La primera parte de la pregunta queda contestada, en sentido negativo, fijándose simplemente en el hecho de que la propuesta analizada separa el surgimiento de la fase ilícita respecto de la finalización de los actos que lleva a cabo el autor, lo que evidencia ya que no es el concepto al uso de tentativa acabada (finalización de las actuaciones -activasdel autor) el que contiene el criterio decisorio en la materia (que se ubica en su lugar en la ulterior pérdida del control del riesgo). El discurso viene a sugerir, de hecho, desmantelar el propio concepto de tentativa acabada y predicar el adjetivo (acabada) de la ejecución, sin prejuzgar con ello su carácter delictivo (tentativa). Pero resta aún la segunda parte, esto es, saber si tales categorías continúan siendo necesarias para referenciar a ellas de algún modo los (distintos) criterios decisorios, para lo que sí son usadas por Alcácer. Por ello pueden resultar pertinentes algunas reflexiones relacionadas con el fondo de la cuestión que -se adelanta-apuntarían más bien hacia un criterio unitario en virtud del cual transitar de lo permitido a lo prohibido en el ámbito de lo intentado (la generación dolosa de un nivel de riesgo bastante), obviando en este tema del surgimiento de la ilicitud del intento, pues, las distinciones basadas en -o referenciadas a- las categorías de tentativa inacabada y acabada. Tales consideraciones irán referidas tanto al núcleo del planteamiento, que sitúa la pérdida del control del riesgo como parte de la desvaloración 
del hecho, en la órbita del merecimiento de pena (3.1), como a sus derivaciones aplicativas, por la eventual falta de coincidencia del inicio de ejecución identificado según el criterio que se somete a valoración con un dolo actual que permita imputar a éste el resultado (3.2).

\subsection{Función sistemática de la pérdida del control del riesgo}

a) En el primer ámbito, lo primero que puede llamar la atención -y requerir tal vez una justificación más detenida- es la disparidad de trato que se dispensa a las distintas tentativas punibles, al condicionar el surgimiento de la responsabilidad a la pérdida del control del riesgo solo en un grupo de ellas, pero no en las demás. No habrá tentativa -se dirá- si el autor que ha envenenado el tarro de café de la víctima confiando en que ésta aparecerá dos días más tarde sale a la calle a comer algo con intención de volver, pues conserva el control de un riesgo que no ha abandonado aún dolosamente ${ }^{17}$, como no la habrá tampoco, por la misma razón, si el sujeto permanece junto a la víctima a la que ha atado a las vías del tren que debe pasar al cabo de unas horas, o -cabrá entender- junto a la víctima a la que ya ha envenenado, si conserva en su poder un antídoto a todas luces eficaz (todas, tentativas acabadas). En cambio, sí habrá tentativa si el autor simplemente comprueba al tacto el grosor del cristal instantes antes de levantar la palanca con la que va a romperlo para apoderarse de los objetos del interior ${ }^{18}$ (tentativa inacabada), y ello pese a que -cabría pretextar- sigue conservando el control sobre el riesgo en relación con el delito robo.

A mi entender la pérdida del control del riesgo atañe solo al desistimiento y no a la generación de la responsabilidad, que queda conformada con la mera producción dolosa del riesgo relevante. Puede, naturalmente, considerarse que

17 ALCÁCER GUIRAO, R., Tentativa y formas de autoría ..., cit., p. 191. 18 ALCÁCER GUIRAO, R., Tentativa y formas de autoría ..., cit., p. 72. 
el riesgo no es suficientemente importante para justificar la intervención penal hasta que la probabilidad de salvación del bien haya disminuido seriamente porque la persona a cargo de su control abandona su obligación de contenerlo. Pero faltará tal vez entonces aclarar la razón por la cual eso no tiene por qué ser tenido en cuenta en las convencionalmente denominadas tentativas inacabadas. De modo que, parece, o bien se extiende la exigencia a toda tentativa (y queda entonces sin justificar por qué el legislador incrimina un buen número de otras conductas - tentativas inacabadas-), o bien se acepta que no es la conservación en el propio ámbito de dominio del control del riesgo generado lo que mantiene los actos en la fase preparatoria.

Lógicamente, se apela desde la tesis comentada a la inminencia del peligro como elemento aglutinador común a toda tentativa, y es precisamente la búsqueda de ese loable objetivo (el respeto más escrupuloso del principio de lesividad) lo que motiva el desplazamiento hacia delante de la barrera de punición en ciertos casos (ciertamente una minoría) en los que queda aún lejana la acción pretendidamente típica o la verificación del resultado. Pero la inminencia debe verse en realidad en la entidad y definición suficiente de la amenaza, y no en un factor que es solo secundario o accidental, como es el de la proximidad espacio-temporal, que constituye solo un indicio más de aquella entidad del peligro. La relevancia de los intentos puede reconducirse entonces, a mi entender, a un patrón común sin sobredimensionar el valor obstativo de la proximidad espacio-temporal ni invadir tampoco el espacio del desistimiento, si se contempla el proceso ejecutivo globalmente, de modo que se visibilice la fase omisiva que sucede a los comportamientos activos (únicos estos últimos tenidos en cuenta en la distinción tradicional entre tentativa inacabada y tentativa acabada ${ }^{19}$ ), a efectos de requerir la ausencia

19 Sin perjuicio de que se haya buscado después el paralelismo en la comisión omisiva. 
de actos intermedios hacia la consumación. Así, mientras en unos casos (para un espectador objetivo ex ante -considerando el plan del autor-) el peligro revestirá entidad bastante y aparecerá suficientemente definido faltando solo el comportamiento activo del autor, en otros ocurrirá lo mismo faltando sólo su actitud pasiva. Pero anular ese último comportamiento será ya -si la actuación, omisiva o activa, reúne los requisitos necesarios para ello (ser expresión del principio de máxima seguridad en la salvación)- desistimiento.

En esta cuestión, por tanto, tal vez el trasvase a la totalidad de las tentativas acabadas de los desarrollos doctrinales más elaborados sobre el inicio de la ejecución alcanzados en relación con la autoría mediata no resulte, pues, del todo conveniente. Es cierto que comparten estructura (la autoría mediata ciertamente es, si por alguna razón debe aplicársele inexcusablemente ese criterio binario de clasificación, una tentativa acabada), pero tal vez ello no baste para justificar la total asimilación en este ámbito del inicio de la ejecución, pues existen también diferencias sustanciales que pueden afectar a la definición del peligro bastante, que es a la postre lo relevante. En efecto, en la autoría mediata concurre, como destacan los partidarios de la solución del instrumento, un comportamiento humano y no un mero curso causal ciego, un acontecer mecánico. Por ello, la consideración de la conducta del autor como entidad de peligro enteramente definida puede presentar más dudas en esta clase de autoría, entre otras razones porque no está conceptualmente excluida de raíz la eventual necesidad de delimitación entre autoría y participación, o porque en algunos casos se apreciará dicha autoría mediata aun faltando la realización de actos materialmente preparatorios por parte del instrumento. Tales condicionantes, que pueden requerir efectivamente ajustes en relación con el afloramiento de la tentativa en la autoría mediata, no existen en las tentativas acabadas que solo están pendientes del paso del tiempo, por lo que el peligro puede aparecer ya suficientemente definido desde el primer 
momento para un espectador objetivo ex ante. Los ejemplos académicos resultan una vez más capciosos en este punto: se dice, por ejemplo, que hay un "peligro inmediato" y, por tanto, tentativa en autoría mediata, si un cazador le dice a su compañero que dispare rápidamente sobre unos matorrales que se mueven, ocultando en realidad a una persona. Pero lo que lleva a afirmar la inmediatez -y confunde- es que tal vez falten solo escasos segundos para que la víctima pueda estar muerta. Sin embargo, en realidad -y dejando de lado el hecho de que resulta poco verosímil que se abran diligencias si el segundo cazador no llegó a disparar- ocurre que con esa sugerencia (del cazador 1), por cercana espacio-temporalmente que pueda presentarse el resultado en una de las hipótesis subsiguientes (que el cazador 2 efectivamente dispare), no está suficientemente limitado el haz de aconteceres alternativos, como sí lo estaría si la orden se diese a un robot programado para disparar en esos supuestos, lo que sí permitiría apreciar ya en ese momento el peligro requerido ${ }^{20}$.

b) Una segunda reflexión, que en absoluto parece irrelevante, dimana de la apelación directa al principio de legalidad. La opción que sitúa el inicio de la tentativa acabada

20 Por ello, se insiste, la cuestión del inicio de ejecución en las tentativas acabadas puede presentar matices relevantes respecto de la solución que se considere aplicable en los casos de autoría mediata, aunque estructuralmente resulten asimilables. Sobre el comienzo de la tentativa en esta última en general, en la doctrina española, $c f r$. DEMETRIO CRESPO, E., La tentativa en la autoría mediata y en la actio libera in causa: una contribución al estudio del fundamento de punición y comienzo de la tentativa. Ed. Comares, Granada, 2003; HERNÁNDEZ PLASENCIA, J.U., La autoría mediata en Derecho penal. Ed. Comares, Granada, 1996, a favor de la solución diferenciadora o individualizadora modificada, preconizada por Roxin (p. 104 ss., 115 s.). A favor de la solución individual (o solución del autor mediato), recientemente y con renovados argumentos, véase MARTÍNEZ-BUJÁN PÉREZ, C., La autoría en Derecho penal. Un estudio a la luz de la concepción significativa (y del Código penal español). Ed. Tirant lo Blanch, Valencia, 2019, p. 149 ss., quien llega a dicha solución desde las premisas que informan la concepción significativa. 
en la última acción ejecutiva (activa) del autor, sin esperar a su pérdida de control sobre el riesgo, encaja formalmente en la regulación del art. $16 \mathrm{CP}^{21}$, pues con ella no sólo se da principio a la ejecución, sino que han concluido los actos ejecutivos -activos-, quedando solo esperar al resultado. Esta realidad es reconocida por Alcácer, pero se arguye en contra que dicha conclusión "contradiría el sentido y fin material de dicha regulación, que aspira a limitar el comienzo de la tentativa todo lo posible, vinculándolo a la inmediata realización del verbo nuclear del tipo" ${ }^{22}$. A su juicio, aplicar esta solución para el autor mediato supondría "un innecesario y excesivo adelantamiento de la punición, no distinguiendo valorativamente los casos de tentativa acabada en los que ya se ha incidido en la esfera de la víctima de aquellos en los que el riesgo permanece en el ámbito de control del sujeto".

$\mathrm{Si}$ respecto de las tentativas acabadas en general se produce o no con ese criterio formal un adelantamiento

21 La afirmación pudiera requerir de ciertos ajustes en relación con la autoría mediata, pues es cierto que el art. 16 se redacta pensando solo en la tentativa en la autoría única, no en la coautoría ni en la autoría mediata. Pero sí tiene expresamente en cuenta la tentativa acabada, a diferencia en esto del código alemán, de cuyo $\$ 22$ se afirma con razón que estableció la descripción de la tentativa pensando exclusivamente en la tentativa inacabada de una autoría directa (ROXIN, C., "Der Anfang des beendeten Versuchs", en Festschrift für R. Maurach zum 70. Geburtstag, Müller Verlag, 1972, p. 214).

Con todo, y en relación con la autoría mediata, asiste la razón a MARTÍNEZ-BUJÁN cuando observa, en defensa de la solución del autor mediato para fijar el inicio de ejecución en esta clase de autoría, que con su actuación el hombre de atrás empieza ya "a servirse" del instrumento, dando así cabal cumplimiento, hay que entender, a lo requerido por la combinación de los arts. 16 y 28 y permitiendo apreciar desde ese instante ( en sentido lógico-gramatical (La autoría ..., cit., p. 149 y 151, n. 9).

22 ALCÁCER GUIRAO, R., Tentativa y formas de autoría ..., cit., p. 208, citando a autores que, como Jakobs, han estimado que la aplicación literal de la regulación legal de la tentativa en la autoría mediata -y, por extensión, de la tentativa acabada- "sólo sería adecuada desde el punto de vista jurídico-conceptual, pero materialmente equivocada". 
intolerable de la punición, al punto que autorice a trascender el tenor de la ley, es cuestión que puede no resultar, al menos, tan evidente. Puede parecerlo más fácilmente si se fija la atención en los casos de autoría mediata con previsión de producción del resultado más remota, pero tal impresión disminuirá sensiblemente en las tentativas acabadas con dosis más elevadas de peligro creado (supuestos del tipo: envenenamiento idóneo finalizado, aunque posesión del antídoto eficaz). Sobre ello volveré de inmediato ${ }^{23}$. Pero puede señalarse ya que, aunque la no inclusión del criterio de la pérdida del control para situar la aparición del peligro relevante ciertamente supone no efectuar esa distinción valorativa en sede de injusto, ello no implica sin embargo apostar por un tratamiento homogéneo y monolítico, pues la valoración de las diferencias pueden quedar reconducidas a otros ámbitos. Y, desde luego, la preocupación por la disparidad de trato no parece fundada desde el punto de vista práctico si, presuponiendo la conformación de la responsabilidad por la generación dolosa del riesgo, se acepta trasladar la cuestión al ámbito de determinación de la pena (en lugar de cribarla en sede de tipicidad con un rígido axioma dogmático). La ponderación podrá canalizarse entonces a través del "peligro inherente al intento", parámetro del art. $62 \mathrm{CP}$ en el que podrán tomarse en consideración la entidad del riesgo creado, la lejanía del resultado o la dificultad para su desactivación. En cualquier caso, debe recordarse que en la tesis comentada el obstáculo que representa la lejanía del resultado acaba siendo irrelevante, pues la "inmediatez" con la realización típica acaba fiándose a un criterio marcadamente subjetivo. Lo determinante será que el autor decida abandonar el riesgo. Con ello, la voluntad individual parece adquirir un excesivo peso en la aplicación del criterio definidor del inicio de ejecución.

c) En tercer lugar, conviene recuperar la afirmación que presupone el adelanto excesivo de la punición de forma

23 Infra, c). 
generalizada en todos los supuestos en los que no se ha decidido aún abandonar dolosamente el control del riesgo. Aun con la mayor cautela en el respeto del principio de lesividad y en la ponderación de éste con los fines preventivos, se debe ser especialmente consciente de que aceptar que la conservación del control del riesgo mantiene congelado el inicio de la ejecución en todos los casos y con ello el surgimiento de la responsabilidad, implica estar dispuestos a aceptar que todo lo ocurrido con anterioridad es un mero acto preparatorio, penalmente irrelevante. Aplicado a los ejemplos clásicos, lo serán: montar y activar un artefacto explosivo en el lugar donde debe estallar horas después, si se conserva el detonador con el que podría desactivarse ${ }^{24}$; atar a la víctima a las vías del ferrocarril hasta varios (¿cuántos?) minutos antes de que pase el tren (sin perjuicio de la detención ilegal, en tanto que tentativa cualificada); dejar preparada una limonada envenenada en el domicilio en el que a diario se la toma la víctima, si faltan horas para su regreso, etc. Todos, actos que no merecerán reproche penal.

Ciertamente, la postura comentada parece no dejar finalmente en el ámbito de la irrelevancia supuestos como los indicados, sino que éstos son rescatados para el ámbito de lo punible a través de la estructura de la comisión por omisión. En casos en los que, por ejemplo, el autor deja preparado un explosivo en un interruptor de luz para que otro lo accione horas después (Mir), esta postura entenderá que no ha empezado la ejecución, pero que no habría obstáculo para atribuir responsabilidad por delito intentado en comisión por omisión. Aquí el deber de garante derivaría de un actuar precedente doloso que, sin embargo, no habría resultado típico $-\mathrm{y}$ por ello no podría reconducirse la imputación a la fase activa- pero la tentativa comenzaría, entonces, en la fase

24 Abstracción hecha ahora, se sobreentiende, de las previsiones específicas que pueda contener un determinado ordenamiento positivo (en nuestro caso, v.g., art. $574 \mathrm{CP}$ ). 
omisiva $^{25}$. No resulta sencillo advertir, de todos modos, en qué forma entraría en juego de ese modo realmente alternativo la responsabilidad por tentativa omisiva (sí, obviamente, en caso de producción del resultado -consumación-), desde el momento en que para su concurrencia se demanda también, con carácter general y congruentemente con lo requerido para la comisión activa, la pérdida del control sobre el riesgo ${ }^{26} ;{ }^{27}$.

En cualquier caso, lo finalmente relevante no es a mi juicio la mejor o peor coherencia del patrón dogmático aplicado para construir la responsabilidad. Sino que, por uno u otro camino (comisión activa u omisiva), se está ventilando justamente eso, la construcción de la responsabilidad, en lugar de, como creo que debiera, la punibilidad de la responsabilidad ya surgida (por la creación dolosa del riesgo). Y esto sí tiene auténtica relevancia desde el momento en que los criterios de imputación que rigen lo primero no gobiernan lo segundo. Sobre esto volveré después ${ }^{28}$, al comentar las

25 ALCÁCER GUIRAO, R., Tentativa y formas de autoría ..., cit., p. 181.

26 ALCÁCER GUIRAO, R., “Comienzo de la tentativa ...”, cit., p. 26: "sólo (...) cuando el sujeto abandona el control sobre el foco de riesgo pasará éste a ser normativamente prohibido, momento en que comenzará la tentativa".

27 En cualquier caso, el autor viene a considerar igualmente viable reconducir la imputación al delito comisivo, apoyándose en la identidad estructural entre la comisión y la omisión. Desde un punto de vista normativo, se afirma, ambas estructuras resultarían intercambiables. Si la responsabilidad deriva de una competencia de organización del autor (Jakobs), "es indiferente que el peligro que emane de esa esfera de organización se deba a una aplicación de energía en el mundo exterior o a permitir que un riesgo creado o mantenido dentro de esta esfera trascienda la misma" (Tentativa y formas de autoría ..., cit., p. 182). De modo que "si el riesgo ha sido generado activamente y dirigido dolosamente a lesionar un bien jurídico, podrá afirmarse indiferentemente un delito omisivo o comisivo, aunque el momento en que ese riesgo sale del ámbito de organización del autor (por abandonar éste el control sobre el mismo) y pasa de permitido a prohibido se produce en una fase omisiva de la conducta (unitaria) completa" (Tentativa ..., cit., p. 183). 
derivaciones aplicativas del planteamiento y los problemas de imputación al dolo del resultado.

d) En definitiva, y como ya he adelantado, la opción comentada funde la ausencia de creación del peligro (a mi juicio, tentativa) con la posibilidad de revertirlo. Entiende, en suma, que el peligro penalmente relevante no existe con carácter previo a la pérdida de su control, pues es ése el momento en el que trasciende por primera vez la esfera de organización del autor. Sin embargo, nótese, tal afirmación lleva ya implícita la consideración de que el peligro existe primero, y trasciende la esfera del autor después, de modo que no resulta en absoluto neutral en la explicación de por qué hay que aguardar a la pérdida del control para configurar la desvaloración del hecho, sino que encierra ya la opción ideológica sobre el papel que debe jugar dicha pérdida (o abandono).

Una explicación alternativa, que resulta a mi juicio preferible, situaría el afloramiento de la tentativa en la generación dolosa de una cuota suficientemente perfilada de peligro, concretada en función del tipo de la Parte Especial, habilitándose desde ese instante el término para el desistimiento, institución con la que debe relacionarse realmente la pérdida del control del riesgo creado $^{29}$. No puede desconocerse que

29 En algún pasaje de su trabajo ALCÁCER parece rebatir la ubicación de la pérdida de control en el terreno de la desistencia, cuando se ocupa de contestar la objeción formulada por Vogler "relativa a que con el criterio de la pérdida del control del riesgo como marco para el comienzo de la tentativa se está operando en realidad con elementos propios del desistimiento". Sin embargo, sus argumentos no van en realidad en esa dirección: "Ciertamente -afirma- en el momento en que el autor abandona el control sobre el riesgo ya no le quedará la opción de un desistimiento pasivo, sino que si quiere desistir de su acción tendrá que volver a recuperar el control sobre el riesgo e impedir que el curso causal continúe (...). Pero ello, ni supone operar con criterios del desistimiento -porque aquí el abandono del foco de riesgo no persigue un fin de hacer desaparecer un posible peligro, sino, todo lo contrario, de crear un peligro, en cuanto que por primera vez trasciende de la esfera de organización del autor-, ni esa concepción impide la posibilidad de 
el apoyo directo en la entidad del peligro ha sido cuestionado (si bien, debe decirse, especialmente con el trasfondo de la legislación alemana, que solicita inmediatez respecto de la realización del tipo) por ser esta magnitud un continuum, que no permitiría ser seccionado en grados, lo que justificaría la búsqueda de un hito concreto donde anclar la barrera de separación con la preparación impune. Sin embargo, la incertidumbre en la concreción del punto crítico - que se disipa razonablemente a mi juicio respecto de cualquier tentativa con la exclusión de comportamientos (activos o pasivos) intermedios- también persiste en la concreción del momento de abandono del control, con los inconvenientes añadidos de la subjetivización del criterio en la determinación del inicio de la tentativa.

\subsection{Derivaciones aplicativas}

La opción acogida, como se anunciaba, tiene una innegable trascendencia en la concreción de los efectos derivados. Como se ha visto, la tesis que sitúa como hito determinante para el surgimiento de la responsabilidad la pérdida del control del riesgo llevaba a concluir que, en los casos en los que el resultado acaba produciéndose tras una pérdida involuntaria de aquel control (por razones ajenas a la voluntad del agente), debe apreciarse la comisión imprudente del delito. La fusión en un solo elemento de la creación del riesgo

desistimiento. Indudablemente, sí se imposibilita el desistimiento pasivo (...)" (op. ult. cit., p. 183 s.).

En realidad, el desistimiento a través de la inacción sí es posible en las convencionalmente denominadas tentativas acabadas, respondiendo la correspondencia entre la clase de tentativa y la modalidad activa o pasiva del comportamiento desistente a un prejuicio que debe ser superado en favor de la acción óptima de salvación. Pues bien, la argumentación reproducida se inserta en ese esquema de pensamiento y, en cualquier caso, se ocupa de reiterar (sin explicar) que la inacción -dejando escapar el control- pertenece aún a la etapa de generación de responsabilidad (a crear un peligro que aún no existe), y no a la de exclusión de la punibilidad por la responsabilidad ya surgida. 
y de la pérdida de su control (entendiendo que el objeto al que el dolo debe referenciarse, de forma actual, abarca hasta el momento en que el peligro se abandona voluntariamente a su curso) conduce efectivamente, al advertir la falta de coincidencia temporal entre el dolo y la acción típica completa (desde ese punto de vista), a negar la imputación al dolo del resultado producido y, por ende, la imputación dolosa. Desde esta perspectiva, veíamos, faltará un dolo de tentativa acabada (o dolo de consumación). Si nos apoyamos en los ejemplos que ya nos han acompañado, así sucederá en el momento en el que el autor deje preparada la limonada envenenada en la cocina en la que habitualmente se la toma la víctima, o deje activado el explosivo en el lugar en el que debe detonarse, por el simple hecho de que tenga pensado volver y mantenga por tanto abierta la posibilidad de verter finalmente la bebida en el fregadero o de desactivar el explosivo.

Pero otra explicación pasa por separar la creación del riesgo y la pérdida de su control, observándolos, por así decir, como sintagmas distintos, con funciones sintácticas por lo tanto diferenciadas en la afirmación del entramado necesario para asociar la pena a un determinado comportamiento. Es verdad que, puede argumentarse, la percepción del riesgo (y también éste, objetivamente) aumenta cuando quien debía operar como barrera para su contención abandona voluntariamente (o pierde involuntariamente) su control. Parece obvio que la ausencia de medidas de precaución o contención hace más probable que el peligro desemboque en lesión ${ }^{30}$. Pero lo que ello nos dice es precisamente que el riesgo existe, y es por eso que puede aumentar ${ }^{31}$. El ordenamiento especifica (con mayor o menor precisión, esa es otra

30 GIMBERNAT ORDEIG, E., "Causalidad, omisión e imprudencia", $A D P C P, 1994$, p. 38.

31 Si la preexistencia no se debe a la actuación voluntaria del propio agente, esa progresión hasta un punto intolerable puede ser determinante del inicio de la comisión omisiva. 
cuestión) qué riesgos no deben ser generados, identificando conductas prohibidas que por ser típicas deberán ser evitadas. De modo que cabe también entender, sin contrariar la redacción legal, que existirá un injusto doloso si el sujeto decide realizarlas conociendo tal riesgo, y atribuir otra función a la conservación de su control, cuyos efectos repercutirían concretamente en el ámbito del desistimiento, facilitándolo o dificultándolo.

De este modo, lo primero que deberá comprobarse será, en efecto, la posibilidad de imputar al dolo el resultado (ya objetivamente imputable a la acción). Pero para ello, cabrá entender que concurre el necesario dolo de consumación ${ }^{32}$ si el sujeto se representa (abarca intelectualmente) que el comportamiento llevado a cabo será interpretado, conforme al inequívoco significado social derivado de las circunstancias acompañantes ${ }^{33}$, como expresivo de un peligro suficiente que lo convierte en típico y debe, por ello, ser evitado. $\mathrm{Y}$, continuando con los mismos ejemplos ya manejados, así cabe entender que sucede -coincidiendo en el mismo momento dolo y acción típica- si se ha activado el explosivo en el lugar previsto para la detonación, se ha dejado la limonada envenenada lista en el lugar donde a diario es ingerida, o se ha atado a la víctima a las vías del tren, aunque en todos esos casos el resultado previsiblemente no vaya a producirse hasta al cabo de un par de horas y aunque el agente conserve por ello la posibilidad de (y hasta la predisposición a) revertir la situación: si en ese lapso, por ejemplo, interviene la policía y desactiva el explosivo, desata a la víctima o encuentra la limonada envenenada en casa de la víctima, habrá tentativa, aunque el autor tuviese entre sus planes volver. A partir de ahí, naturalmente la ascendencia que se conserve sobre el riesgo creado está llamada a tener su relevancia, pero en

32 Expresión que me parece preferible a la de dolo de tentativa acabada, aunque sean utilizadas como sinónimas.

33 Véase, RAGUÉS VALLĖS, R., El dolo y su prueba en el proceso penal, Bosch, Barcelona, 1999, pp. 177 ss. 
un ámbito distinto al de la generación de la responsabilidad: el de la eventual exclusión de la respuesta penal programada para el injusto realizado. Con la creación del riesgo con dolo de tentativa acabada, según lo expuesto, se consuma la tentativa, habilitándose desde ese instante el terreno para el desistimiento, que no se cerrará hasta el momento de la terminación del delito intentado, lo que se produce solo cuando tal situación de riesgo se ha tornado objetiva y definitivamente irreversible ${ }^{34}$.

Lo auténticamente relevante en toda esta cuestión reside en el hecho de que en esta nueva fase, perteneciente a la valoración de la necesidad de pena y no a la determinación de su merecimiento, no rigen los mismos principios que impedirían atribuir responsabilidad por el resultado, puesto que el desistimiento constituye una mera oportunidad excepcional que se concede al sujeto por razones político-criminales preventivas, y no de justicia, para quedar exento de pena por el injusto ya realizado. De modo que no existe ni un derecho a desistir, ni un límite de inexigibilidad al requisito de la prestación óptima ${ }^{35}$, ni tampoco infracción de principio alguno por la imputación del resultado dolosamente generado. En el caso, citado, en el que el sujeto que ha dejado conectado el explosivo a un interruptor de la vivienda de la víctima sale a comer algo confiando en que dicha víctima aparecerá dos días más tarde, y es sin embargo atropellado por un vehículo, lo que le impide volver a tiempo para proceder a la desactivación, no faltará en realidad, según lo expuesto, el dolo actual sobre el comienzo de la acción típica y se estará, en consecuencia, ante un delito doloso (y no ante una mera imprudencia producto último de una consumación anticipada, en la que el autor no se habría representado adecuadamente la inmediatez del peligro por el hecho de considerarlo

34 Infra, II.

35 ALCÁCER GUIRAO, R., ¿Está bien lo que bien acaba? La imputación de la evitación del resultado en el desistimiento, Ed. Comares, Granada, 2002 , p. 87. 
controlado $\left.{ }^{36}\right)$. Y la misma línea de solución deberá arbitrarse para supuestos de desviación en la ejecución, como el siguiente de aberratio ictus, variante del anterior, propuesto asimismo por Alcácer ${ }^{37}$ : si A deja la comida envenenada lista para que la víctima B se la tome, y sale a la calle a hacer unas gestiones, pero en el ínterin entra en casa un técnico de calefacciones al que el portero le ha abierto la puerta, tomándose éste parte de la comida que encuentra sobre la mesa, no habrá que apreciar solo un homicidio imprudente, por entender que la tentativa respecto de B no había comenzado, sino un concurso entre ese delito imprudente (si se vulneró efectivamente el deber de cuidado) y la tentativa.

Desde estos mismos presupuestos también parece matizable, en fin, la distinción que se efectúa en el seno de los casos en los que se produce no ya la pérdida involuntaria, sino el abandono voluntario del control del riesgo, separando entre aquellos que no conllevan una pérdida objetiva del mismo (tentativa acabada pero incompleta) y los que sí la conllevan (tentativa acabada completa) ${ }^{38}$. En ambos casos, sin distinción, si se produce el resultado objetivamente imputable a la acción, no parecen encontrarse méritos suficientes para negar el dolo de tentativa acabada conforme a lo explicado. En el primer subgrupo, el sujeto dispuso de una oportunidad sencilla para llevar a cabo la acción óptima de salvación, pero no la aprovechó (p.e., disponía de la llave para volver al piso y desactivar sin contratiempos el explosivo colocado). En el segundo subgrupo, desplegar la opción óptima de salvación requería esfuerzos extraordinarios para recuperar un control objetivamente perdido. Pero en ambos, si no se consigue la evitación, será igualmente imputable el resultado al dolo, y deberán ser tratados como delitos

36 Esta otra lectura de la situación, como se ha expuesto, puede verse en ALCÁCER GUIRAO, R., Tentativa y formas de autoría ...., cit., p. 196.

37 ALCÁCER GUIRAO, R., Tentativa y formas de autoría ..., cit., p. 192.

38 ALCÁCER GUIRAO, R., Tentativa y formas de autoría ..., cit., p. 204. 
dolosos consumados (con, en su caso, la atenuante análoga a la de reparación si se malogró el desistimiento), en lugar de reservar este tratamiento solo al segundo subgrupo de casos, y apreciar un concurso entre la tentativa dolosa y un delito imprudente en el primero.

\section{Tentativa terminada y preclusión del desistimiento}

1. La cuestión acerca del momento inicial de la tentativa, en general (y no solo en relación con el específico grupo de supuestos comentados en el epígrafe anterior -tentativas acabadas-) constituye, con razón, uno de los ítems fundamentales en la dogmática del delito intentado, pues con ella se determina su propia emersión como comportamiento penalmente relevante, disociándolo de la preparación impune. Sin embargo, otra cuestión no menos importante y en cambio tradicionalmente menos atendida es la relativa al momento final de la tentativa, entendiendo por tal el que nos debe indicar hasta cuándo se puede desistir válidamente del intento. A esta pregunta tampoco es capaz de responder la distinción entre tentativas inacabadas y tentativas acabadas en el sentido usual. $\mathrm{Ni}$, en realidad, está en condiciones de hacerlo adecuadamente ninguna de las categorías al uso entre las que de uno u otro modo se han relacionado con la etapa final de la forma imperfecta de ejecución. Ni las más tradicionales (sea la aludida de la tentativa acabada-ni, por supuesto, la ya superada de la frustración-, o la tentativa fracasada) ni las de corte más reciente, como la tentativa perfecta ${ }^{39}$. Pues el desistimiento resulta en abstracto posible tanto si se ha llevado a cabo todo lo necesario para ocasionar el resultado como en caso contrario (tanto en tentativas acabadas como inacabadas, por consiguiente); tanto si el autor ha conservado el control del riesgo, percibiendo como segura en todo momen-

39 Sobre ello, GILI PASCUAL, A., "Pérdida de control sobre el riesgo creado y terminación del delito intentado", InDret 2/2012. 
to una eventual acción salvadora propia, como si ha perdido esa condición, pasando a ser incierto el desenlace para todos (esto es, tanto en tentativas imperfectas como perfectas ${ }^{40}$ ). E incluso resulta abstractamente imaginable en supuestos en los que el autor ha llegado transitoriamente a la convicción errónea de que su meta se ha alcanzado ya o, en sentido totalmente opuesto, no puede ya alcanzarse, comprobando con posterioridad que o bien el resultado no se había producido todavía o bien que el riesgo permanecía objetivamente activo. En determinadas acepciones, por tanto, cabe también el desistimiento respecto de la denominada tentativa fracasada ${ }^{41}$.

En realidad, la posibilidad de desistimiento queda habilitada desde el primer instante en que emerge el peligro suficiente para dar vida a la tentativa (no, por tanto, cuando se abandona voluntariamente su control, como se ha explicado anteriormente contestando a determinados planteamientos en relación con el inicio de ejecución en la tentativa acabada), y dicha posibilidad se mantiene abierta mientras subsiste objetivamente el riesgo apto para provocar la consumación. Por ello, para expresar esta última idea, resulta a mi juicio conveniente manejar un concepto esencialmente objetivo de terminación, en virtud del cual considerar tentativa terminada aquella en la que el peligro, habiendo contado ya con plena potencialidad lesiva en un juicio ex ante, la ha perdido definitivamente, cerrando así objetivamente la posibilidad de evitación del resultado, bien porque tal peligro se haya concretado efectivamente en él (consumación), bien porque, en distinto sentido, se verifique la imposibilidad de alcanzarlo con ese intento ${ }^{42}$-sin perjuicio, se entiende, de que el

40 Sobre estas categorías, BENLLOCH PETIT, G., "De cómo el injusto de la tentativa va variando según avanza la ejecución y de cómo esto incide en la fundamentación de la impunidad por desistimiento", Rev. Peruana de Jurisprudencia, núm. 24, 2003, pp. 141 a 170.

41 GILI PASCUAL, A., "Pérdida de control ...", cit., p. 31.

42 Por ejemplo, si el artefacto explosivo programado estalló sin alcanzar a la víctima; o si el disparo se desvió unos centímetros de su objetivo. 
parámetro colectivo en la interpretación del desistimiento permita excluir sus elementos en un momento previo a la disolución objetiva del riesgo ${ }^{43}-$. En contextos de plurintervención, en la medida en que lo permite la opción legal de un desistimiento mediante esfuerzo serio en pro de la evitación del resultado, cabrá apreciar el desistimiento también en supuestos en los que el agente desconocía que el resultado estaba ya en vías de ser evitado por otros medios, pero ello siempre con anterioridad a la evitación objetiva (en escenarios, por tanto, de subsistencia objetiva del peligro $)^{44}$.

2. El posicionamiento explicado tolera, como se ve, eventuales pérdidas transitorias del control sobre el riesgo, permitiendo la impunidad por desistimiento si existe una recuperación posterior que permita aún el despliegue de la acción óptima de salvación, en tanto subsista objetivamente la potencialidad lesiva ${ }^{45}$. Ello puede resultar a lo mejor polémico, por cuanto el sujeto ha completado en esos casos el pleno desvalor de acción, quedando solo a expensas de un resultado respecto de cuya producción no se ostenta ya ningún control, lo que podría incentivar tal vez la apreciación en su lugar de un episodio cerrado, indesistible. No obstante, existen dos buenas razones para que ello no deba considerarse así:

43 Así, si el hecho es descubierto estando pendiente aún el resultado: éste podría ser ciertamente impedido aún por el agente, pero faltará la voluntariedad, que es también requisito de la exención. Esta limitación temporal fue, curiosamente, prevista expresamente por el derecho positivo alemán en su redacción anterior, que exigió que la acción de impedimento tuviese lugar en un momento anterior al descubrimiento del hecho ( $\$ 46 \mathrm{StGB}$, a. r.).

44 GILI PASCUAL, A., Desistimiento y concurso de personas en el delito, Ed. Tirant lo Blanch, Valencia, 2009, p. 233 ss.

45 Lo que no significa que tal posibilidad esté sistemáticamente al alcance del autor, pues si deja pasar la opción más segura de salvación en un momento 1, deberá encontrar una opción equivalente en un momento 2 para acceder a la impunidad. En este sentido, el retraso en la adopción de la medida óptima solo puede jugar en contra del desistente. 
a) En primer lugar, el fundamento de la exención aquí acogido, por cuanto no impide que un comportamiento verificado tras la recuperación del control del riesgo pueda subrogarse válidamente en el lugar de la pena, siempre, eso sí, que pueda seguir siendo expresión de la acción óptima de salvación (en este sentido, el retraso en su adopción juega en contra del desistente), y se trate, claro está, del mismo riesgo (identidad de tentativa). Veamos algo más pausadamente los componentes de la anterior afirmación:

A mi entender el fundamento de la institución del desistimiento no debe localizarse en la anulación de los presupuestos de la pena (en particular, en el desvanecimiento del injusto), sino que resulta compartible, en cambio, la opinión que sostiene que la exención se explica mejor localizando su razón de ser no en el hecho de que la pena se torne inmerecida, sino innecesaria, haciéndose descansar la justificación de la impunidad en los fines de aquélla ${ }^{46} \mathrm{y}$, en particular, en una

46 ROXIN, C., "Sobre el desistimiento de la tentativa inacabada", en Problemas básicos del derecho penal (trad. de D.M. Luzón). Ed. Reus, Madrid, 1976 (del original publicado en Heinitz-FS, Berlin, 1972), p. 266 s. Alude Roxin tanto a la ausencia de razones preventivo generales (por cuanto no se produce el resultado) como preventivo especiales (puesto que el autor ya ha vuelto a la legalidad). No obstante, tanto las exigencias preventivo generales negativas como las preventivo especiales deben ser matizadas. Estas últimas, en la medida en que la impunidad por desistimiento en nada depende de un pronóstico individual sobre el desistente y su potencial criminal (SCHMIDHÄUSER, E., AT, 1984, $11 / 69$, p. 365), confirmando tanto la existencia de la tentativa cualificada como del llamado desistimiento parcial la desvinculación del desistimiento respecto de este fundamento (vid. GARCÍA PÉREZ, O., $L a$ punibilidad en el Derecho penal, Aranzadi, 1997, p. 151). Tampoco es sin más sostenible que la prevención general negativa deje de tener sentido en supuestos de desistimiento, pues siempre cabe argumentar un mayor efecto intimidatorio y protector del bien jurídico si queda constancia de que la pena merecida se impondrá en todo caso. Incluso se ha sugerido, en este sentido (JAKOBS, G., "La conducta de desistimiento", en Homenaje al Prof. Dr. Gonzalo Rodríguez Mourullo. Ed. Thomson-Civitas, Madrid, 2005, p. 551), que la previsión de impunidad por desistimiento no desincentivaría el delito, sino que antes cabría pensar que lo 
especial valoración en ello de la prevención general positiva y de la idea a ella asociada en virtud de la cual el recurso a la sanción resulta innecesario en los casos de desistimiento para estabilizar la vigencia de la norma que prohíbe la tentativa, revirtiendo la demanda de respuesta que aconsejó su inicial defraudación ${ }^{47}$.

En ese escenario, en el que el desistimiento operará como subrogado de la pena, la evitación del resultado (el requisito de la eficacia del desistimiento) no constituye sólo un elemento accesorio -no conceptual o esencial-, sino un componente sustancial e irrenunciable, pues solo la ausencia del resultado lesivo será capaz de imprimir al hecho una menor trascendencia social, pudiendo la acción de desistimiento revocar completamente la defraudación de la vigencia de la norma ${ }^{48}$ y operar así como auténtico subrogado de la pena.

induce. Subsisten con mayor claridad, en cambio, las razones de prevención general positiva.

47 Si en lugar de primar la perspectiva colectiva, de vigencia de la norma, en la comprensión del desistimiento se pone el acento en el bien jurídico (perspectiva, en cualquier caso, que no significa que el planteamiento aquí seguido desatienda), la razón de ser de este instituto tenderá a encontrarse más en lo que de estímulo para la protección de aquel bien jurídico pueda tener. Desde el punto de vista aquí acogido, en cambio, ese intento de insuflar desde el sistema nuevas energías motivadoras para el respeto de la norma que prohíbe la consumación (ese estímulo para la protección del bien) se torna más bien en efecto reflejo de la inclusión de una previsión de impunidad por desistimiento, pero no en fundamento del mismo. De todos modos, no cabe objetar con carácter general que carezca de sentido una nueva motivación sobre la base de que ya se desatendió una primera, pese a que ofreciera incluso una impunidad segura y no meramente potencial -JAKOBS, G., "La conducta de desistimiento", cit., p. 551-, pues el autor se encuentra ante una nueva situación, en la que ya ha hecho algo punible (merecedor de pena), pero no irreparable (irreversiblemente necesitado de pena), lo que bien puede justificar el recurso a una nueva motivación.

48 ALCÁCER GUIRAO, R., "La reparación en Derecho penal y la atenuante del artículo $21.5^{\circ} \mathrm{CP}$. Reparación y desistimiento como actos de revocación". Revista del Poder Judicial. $3^{\mathrm{a}}$ época, nº 63, 2001, III, p. 101. 
Desde luego, si la innecesariedad se valora contemplando el desistimiento desde la perspectiva del bien jurídico ${ }^{49}$, parecería en principio evidente que su configuración reclama la eficacia como requisito para poder conceder la impunidad, pues mal se entendería que una acción efectivamente lesiva para el bien tutelado se condonase a cambio de otra no efectivamente salvadora ${ }^{50}$. Pero también si esa innecesariedad se valora atendiendo especialmente a la dimensión colectiva, a la vigencia de la norma - posición con la que muestran su mayor afinidad estas líneas a la hora de aproximarse a la concreta figura del desistimiento-, la conclusión parece obligada, y ello, si cabe, con mayor rotundidad que desde la perspectiva anterior. Pues en efecto, el decaimiento de la necesidad de pena, esencia que comparten diversos institutos, encuentra en el concreto del desistimiento su específico mecanismo de producción sólo a partir de la evitación del resultado, ya que es justamente su producción la que torna en más visible el quebrantamiento de la norma ${ }^{51}$. De modo que si éste ha terminado produciéndose de forma objetiva y subjetivamente atribuible al agente difícilmente podrá sostenerse, por más que la vigencia de la norma tolere reparaciones simbólicas, que la misma, pese a su infracción, se mantiene intacta y que se ha neutralizado la repercusión psico-social de su total quebrantamiento gracias a una simple acción bien encaminada del infractor pero fallida.

49 En general, pueden reconocerse dos grandes perspectivas con las que abordar la cuestión del desistimiento, según se ponga el acento en el bien jurídico o en la vigencia de la norma. Véase, ALCÁCER GUIRAO, R., "La reparación en Derecho penal ...", cit., p. 101 ss.; del mismo, ¿Está bien ..., cit., p. 48, citando a Weinhold.

50 No obstante, no debe perderse de vista que esta perspectiva en la contemplación del desistimiento conduce a su fundamentación como estímulo a la protección de bienes. De modo que, y en la medida en que el mantenimiento de ese estímulo puede ser conveniente respecto de cualquier comportamiento con potencial de éxito en la salvaguarda del bien, el planteamiento también podría recomendar la ampliación de la impunidad por desistimiento a comportamientos fallidos.

51 ALCÁCER GUIRAO, R., "La reparación en Derecho penal ...”, cit., p. 100. 
Antes al contrario, y desemboco con ello en la cuestión que ahora me interesa subrayar: partiendo siempre de la ausencia de resultado, el planteamiento comentado llevará a exigir mayores requisitos que enriquezcan incluso la calidad de la acción para poder imputarle esa evitación, demandando, en este sentido, que con ella no se dejen activos riesgos residuales que pudiesen haber desembocado en el resultado; llevará a no conformarse, en definitiva, con la máxima que encierra el adagio "bien está lo que bien acaba" ${ }^{52}$. Ese refuerzo exigible en la calidad de la acción de desistimiento para que éste pueda operar realmente como subrogado de la pena -con base en el fundamento de la exención y, debe destacarse, sin apartarse con ello de la letra de la Ley- se traduce en la necesidad de respetar el principio de la máxima seguridad en la salvación, obligando al agente a optar por la acción óptima de evitación, sin conformarse con acciones subóptimas que dejen margen a riesgos residuales o al azar. Solo de ese modo, exigiendo el dominio pleno del curso salvador, sin contentarse con su mera causación, podrá imputarse realmente la evitación a la conducta del desistente, cuestión cuya comprobación es previa -y distinta- a la de la voluntariedad del desistimiento, y requisito necesario para la exención.

Ahora bien, si bien el fundamento de la exención desemboca razonablemente en la exigencia de ese enriquecimiento de la calidad de la acción ("optimidad") para poder atribuirle la evitación y poder hablar en propiedad de un impedimento del resultado, no parece que ese mismo fundamento exija asimismo el mantenimiento constante del con-

52 ALCÁCER GUIRAO, R., ¿Está bien ..., cit., p. 48 ss.

$\mathrm{Si}$, por ejemplo, tras apuñalar mortalmente a su víctima, el autor se limita a dejar entreabierta la puerta del piso, con la esperanza de que algún vecino de la finca pueda pasar a tiempo por el descansillo y advertir la situación, llamando a una ambulancia, no habrá desistimiento aunque lo indicado acabe sucediendo y la víctima salve, así, la vida. Nada tiene que ver para la impunidad, como se ve, que la tentativa sea acabada y que el desistente haya desplegado un comportamiento activo en este caso, puesto que no puede considerarse suficiente. 
trol sobre el riesgo generado para conceder la impunidad por desistimiento, sino sólo la evitación del resultado en aquellos términos.

b) En segundo lugar, aboga a favor de la impunidad tras pérdida transitoria del control el derecho positivo, en la medida en que ofrece margen suficiente para cobijar la anterior lectura acorde con el fundamento de la exclusión de la pena, lo que además convierte a su contraria en una innecesaria interpretación restrictiva contra reo. En efecto, el código español otorga la impunidad a quien "impide la producción del resultado", sin exigencias añadidas en cuanto a la conservación constante del control sobre el riesgo generado en el propio ámbito de dominio y sin identificar otro tipo de circunstancias preclusivas ${ }^{53}$, siendo generalmente aplicado en este sentido por nuestros tribunales. De modo que si -retomando uno de los ejemplos ya manejados- "A" deja conectado el artefacto explosivo a un interruptor de la vivienda de la víctima, que debe ser quien lo acabe accionando al volver por la tarde a su domicilio, y a continuación abandona el lugar en dirección a su ciudad de origen -de modo que no está ya en sus manos regresar a tiempo, antes de que lo haga la víctima-, no hay razón derivada de la letra de la ley para denegarle la impunidad por desistimiento si al día siguiente tiene ocasión de volver aún al lugar de los hechos y, comprobando que, contra pronóstico, el interruptor no fue accionado, desactiva el explosivo. No se tratará, con la ley en la mano, de una tentativa (consumada) con la atenuante de reparación, sino de auténtico desistimiento de la tentativa.

53 Debe señalarse, en cualquier caso, que voces muy autorizadas han considerado lo contrario. Gimbernat, por ejemplo, ha interpretado el apartado primero del art. 16 como presupuesto para la aplicación del segundo, entendiendo de este modo que sólo cabe plantear el desistimiento impune si se verifica el hecho de que no haya sido el azar el que haya decidido la no producción del resultado. En otros términos: se restringe la opción del desistimiento a los casos en los que el control haya permanecido ininterrumpidamente en manos del agente (GIMBERNAT ORDEIG, E., "El desistimiento en la tentativa acabada", $A D P C P, 2006$, p. 30). 
Ciertamente esta opción, que deja el resultado en manos del azar durante un lapso de tiempo, puede chirriar si se contempla el desistimiento desde el punto de vista de la neutralización de lo injusto, lo que naturalmente no se da. Pero no si se contempla como sola causa de exclusión de la pena, lo que -como se dijo (supra, I.3.2)- lo convierte en una simple oportunidad excepcional que se ofrece al sujeto por razones político-criminales preventivas, y no de justicia, para quedar exento de pena por el injusto ya cometido ${ }^{54}$, opción sobre la naturaleza del desistimiento cuyo seguimiento se justifica precisamente por su congruencia con el fundamento de la institución antes explicado.

3. De esta cuestión, la relativa al momento hasta el cual es posible desistir, se ha ocupado recientemente alguna de las voces doctrinales más autorizadas, proponiendo el uso de una nueva categoría, la tentativa irreversible, para concretar su solución ${ }^{55}$. El neologismo dogmático constituye un acierto en la medida en que el término adjetiva de forma muy plástica el intento del que - gráficamente- ya no se puede volver atrás ${ }^{56}$-al margen ahora de que consista o no exactamente en eso el desistimiento-, y a la vez se separa de las categorías ya existentes, que pueden tener algo en común con esa idea, pero que se encuentran muy manidas e impregnadas de connotaciones distintas, de modo que su aprovechamiento

54 ALCÁCER GUIRAO, R., ¿Está bien ..., cit., p. 87.

55 MOLINA FERNÁNDEZ, F., "Tentativa irreversible y desistimiento impropio", en CANCIO MELIÁ et alter (ed.), Libro Homenaje al Prof. Dr. A. Jorge Barreiro, vol. I, UAM, Madrid, 2019, p. 655 ss.

Esta terminología puede verse ya en MOLINA FERNÁNDEZ, F., "Formas imperfectas de ejecución del delito", en Memento práctico penal, Francis Lefebvre, Madrid, 2017, Cap. 11, marg. 2760 (tentativa irreversible) y marg. 2817 (desistimiento impropio), con algunas diferencias en su contenido.

56 Se refería también a la irreversibilidad de la tentativa SERRANO GONZÁLEZ DE MURILLO, J.L., “'Tentativa fracasada existiendo posibilidades de realizar aún el tipo?", $R D P C, \mathrm{n}^{\circ} 16,2005$, p. 149. 
no haría sino reclamar constantes precisiones a cada paso (un ejemplo próximo puede encontrarse en la importación del concepto alemán de tentativa fracasada, usada en sentidos distintos ${ }^{57}$, propios e impropios, y con marcadas connotaciones subjetivas). En todo caso, hay que advertir a renglón seguido que el significado del que se dota a la tentativa irreversible no aporta una solución coincidente con la anteriormente expuesta, lo que-amén de recomendar mantener para esta última la expresión tentativa terminada ${ }^{58}$, facilitando así al menos su identificación y crítica-, requerirá exponer las líneas fundamentales del tratamiento que resulta de operar con este nuevo concepto. A la postre, como concluía en otro $\operatorname{lugar}^{59}$, la cuestión terminológica resulta secundaria, siendo lo importante clarificar la solución.

Pues bien, el planteamiento aludido, propugnado por Molina $^{60}$, sitúa el momento final de la tentativa, entendido en el sentido antes indicado, preclusivo del desistimiento ${ }^{61}$, en aquel en el que el agente pierde el control sobre el riesgo creado, "momento en el que el hecho deja de ser del sujeto y pasa a pertenecer al azar", en tesis en esto coincidente con la

57 Sobre sus diversas acepciones, SERRANO GONZÁLEZ DE MURILLO, J.L., op. cit., p. 139 s.

58 Aunque presente inconvenientes. Por un lado, por la sinonimia del adjetivo con el usado en la tentativa acabada, lo que tal vez puede predisponer a la confusión con una categoría que nada tiene que ver. Por otro, porque la expresión "terminación de la tentativa", con esos términos, también se ha usado para tratar cuestiones absolutamente distintas de ésta (p.e., FARRÉ TREPAT, E., La tentativa..., cit., Capítulo V, para referirse a "la determinación del momento en que deberán considerarse practicados todos los actos de ejecución que deberían producir el delito" -p. 234 s., en la $1^{\text {a }}$ ed.-).

59 GILI PASCUAL, A., "Pérdida de control ...", cit., p. 32.

60 MOLINA FERNÁNDEZ, F., “Tentativa irreversible...”, cit., p. 673 ss.

61 Si bien solo referido al desistimiento propio, en la adjetivación que realiza el propio autor, pues a partir de ese momento se admite también un desistimiento impropio, al que no se niega tampoco la impunidad. 
definición de la tentativa perfecta propuesta por Benlloch ${ }^{62}$. En tal instante se verificaría el desvalor de acción pleno ${ }^{63}$, correspondiente al proceso ejecutivo global, es decir, al que incluiría no solo la fase activa sino también la fase omisiva posterior (esta última habitualmente invisibilizada o, al menos, infravalorada -según el autor- por un sesgo común en la dogmática penal). Y dicho instante sería también el que definiría la aludida tentativa irreversible, denominación que se otorga a aquella que ha dado comienzo (no sería tentativa en otro caso) pero en la que el autor mantiene el control del hecho ${ }^{64}$, lo que quiere decir "que no se producirá el resultado si el autor quiere evitarlo ${ }^{65}$. Este concreto Rubicón, no obstante, marca el punto final solo para un posible desistimiento propio $^{66}$, en la terminología del autor. Pero la posibilidad de desistir se desplaza, a partir de ahí, al ámbito del que denomina desistimiento impropio, categoría que abrazaría "cualquier acto posterior a la tentativa irreversible que reduzca el desvalor material del hecho delictivo", representando una "compensación parcial o total" de dicho desvalor ${ }^{67}$. En el concreto caso de que tal acción posterior consista en la evitación del resultado, conviene señalarlo expresamente, tal desplazamiento al campo del desistimiento impropio no conlleva en la propuesta de Molina la denegación de la impunidad con las herramientas existentes de lege lata.

62 BENLLOCH PETIT, G., op. cit., p. 141 ss.

63 MOLINA FERNÁNDEZ, F., "Tentativa irreversible...", cit., p. 674.

64 No puede dejar de llamarse la atención sobre el hecho de que ese mismo instante, el de la pérdida del control, sea usado desde distintas posturas en unos casos para retrasar el propio inicio de ejecución -en la tentativa acabada, como se ha visto (supra, I.2)-, mientras que en otros se proponga no ya para determinar el surgimiento mismo de la tentativa, sino como último instante en el que poder desistir de ella.

65 MOLINA FERNÁNDEZ, F., "Tentativa irreversible...”, cit., p. 676.

66 Que efectivamente ya no será posible tras la tentativa irreversible (MOLINA FERNÁNDEZ, F., "Tentativa irreversible...,", cit., p. 674, n. 23).

67 MOLINA FERNÁNDEZ, F., “Tentativa irreversible...”, cit., p. 678 y 680. 
En relación con este planteamiento, ciertamente cabe considerar en un determinado sentido que el momento decisivo que determina cuándo un sujeto ha trasladado definitivamente a los hechos una decisión firme de llevar a cabo una acción peligrosa se da cuando pierde el control sobre el hecho, siendo a partir de entonces inseguro que pueda influir en el proceso; de modo que puede también afirmarse, en ese concreto sentido, que hasta entonces sólo tenemos una elección provisional, y por ello que el desvalor de acción/omisión no está completo ${ }^{68}$. Ello -se sobreentiende- dejando claro en todo momento que de lege lata se castigan (y el legislador puede legítimamente castigar) supuestos en los que no se ha completado ese desvalor pleno de acción (así, las tentativas inacabadas y otras, acabadas). Pero lo que en mi modesta opinión queda sin aclarar suficientemente es la conexión de ese instante con el momento hasta el cual debe considerarse posible acceder a la impunidad por desistimiento; la razón por la cual deba ser ése un momento determinante (no lo es desde el fundamento de la exención aquí seguido), máxime si su fijación no comporta después la exclusión a partir de entonces de la exención (que queda, parece, amparada en un desistimiento impropio). Por eso, la ubicación del desistimiento todo en el campo del decaimiento de la necesidad de pena, sin querer ver parte de él como reversión de aspecto alguno del injusto, puede ser, tal vez, otra opción, que disuelve algunas de las paradojas. Otra alternativa, claro, pasa por promover de lege ferenda la supresión de la impunidad por desistimiento en los supuestos en los que no encaja como acto de justicia o reversión de lo injusto, exclusión que llega a proponer Benlloch en relación con la categoría de la tentativa perfecta $^{69}$.

68 MOLINA FERNÁNDEZ, F., “Tentativa irreversible...”, cit., p. 676.

69 En particular, el autor la propone en relación con "bienes personales de lesión irreversible (como la vida) o potencialmente irreversible (como la integridad corporal)", ampliable a "algún bien jurídico supraindividual 
4. Por lo demás, interesa llamar la atención sobre el hecho de que con el criterio alternativo aquí defendido, como ha podido verse, la respuesta a la cuestión relativa a hasta cuándo cabe desistir válidamente (accediendo a la impunidad) no debe esperarse que surja de la pugna entre las teorías del acto individual (Einzelakttheorie) y de la consideración global (Gesamtbetrachtungslehre) en los términos en que puede haberse planteado en otras latitudes, en un debate siempre mediatizado por la atención a la representación del autor (su finalidad, su plan, su creencia tras la ejecución del último acto) por mor de las exigencias de un concreto contexto legal.

En esto me parece especialmente relevante destacar que en general deben manejarse con cautela, por lo dicho, los desarrollos doctrinales obtenidos al amparo de otro tipo de legislaciones que, como la alemana, priman por un lado el criterio propiamente subjetivo en la definición de la tentativa así como en la caracterización de ésta como inacabada o $\operatorname{acabada}^{70}$ (a la vez que, por otro lado, deducen esta última

de singular importancia siempre y cuando la lesión del mismo sea asimismo irreversible o potencialmente irreversible" (BENLLOCH PETIT, G., op. cit., p. 169 s. y n. 65).

70 Conforme al $\$ 22 \mathrm{StGB}$, la tentativa existe en ese ordenamiento cuando el autor se dispone, según su propia representación del hecho (nach seiner Vorstellung von der Tat), a la realización del tipo de forma inmediata, con lo que su percepción se convierte en elemento central para la definición de lo punible. Con ese trafondo, las precisiones doctrinales -y jurisprudenciales- han evolucionado en ese país contestando a preguntas que no se plantean en los mismos términos en el derecho español. La primera, completamente lógica con aquella regulación, es la relativa al momento en que debe constatarse esa necesaria representación del autor, cuestión que dio lugar a la sucesión de dos planteamientos antagónicos, la teoría del plan del autor (Tatplantheorie) y la posterior del horizonte del desistimiento (Rücktrittshorizont), que no son trasladables sin más a nuestro ámbito. La primera, de cuño jurisprudencial, situaba dicho momento en el inicio de la actuación, tomando en consideración lo que el autor se habría representado como necesario conforme a su plan inicial. Sus destacados inconvenientes (favorecimiento del delincuente más calculador, problemas probatorios, descuido del peligro 
distinción de la regulación del desistimiento, configurándola, por tanto, a la medida de esta sola cuestión $\left.{ }^{71}\right)$. En la cuestión que ahora nos ocupa hay que aproximarse con cautela, en particular, a la dicotomía entre las mencionadas teoría del acto individual y teoría de la consideración global. Debe tenerse en cuenta que se trata de soluciones (contrapuestas) ceñidas a un problema específico, cual es el de la identificación de la identidad de la tentativa en supuestos de reiteración de actuaciones, y ello en el marco de la denominada tentativa fracasada en sentido impropio, esto es, en supuestos en los que la producción del resultado delictivo falla en los precisos términos planteados por el agente, aunque éste sigue considerando que el objetivo delictivo sigue siendo factible de forma

objetivo) acabaron dando paso al mencionado criterio del horizonte del desistimiento, que pasa a constatar la representación del autor no conforme al plan inicial, sino tras el último acto realizado, permitiendo aún, si es el caso, el desistimiento pasivo respecto de una tentativa que se considerará inacabada.

Se coincide en señalar que este segundo planteamiento desembarcó en la jurisprudencia alemana, cambiando el punto de vista hasta entonces imperante, con una resolución de 3 de diciembre de 1982, en el conocido como caso del estrangulamiento o del compañero de vivienda: Würgungs- o también Mitbewohner- Fall (BGHSt 31, 170): el acusado acuchilló a su compañera, a la que había sorprendido robando, y pasó también a estrangularla, retirándose después. El LG había desestimado el desistimiento de una tentativa inacabada, apreciándolo después el $\mathrm{BGH}$. Además de definir la tentativa como inacabada, entendiendo que lo decisivo no es la representación del autor en el momento de comenzar el hecho sino después del último acto ejecutivo, la resolución adopta la tesis de la consideración global del suceso.

71 Las diferencias indicadas (uso de un concepto eminentemente subjetivo y mimetismo con la problemática del desistimiento) justifican las prevenciones aludidas a la hora de acercarse a las soluciones patrocinadas en un ordenamiento distinto que, con todo, no puede negarse que ejerce una poderosa influencia sobre el nuestro también en esta cuestión. Empezando por la propia denominación de las categorías acogida en nuestra doctrina, que es directa traducción de la terminología alemana (beendeter y unbeendeter Versuch) antes que reflejo de la nomenclatura legal, que más bien llevaría a contraponer una ejecución o tentativa total o completa frente a otra parcial o incompleta. 
inmediata con los mismos u otros medios inmediatamente disponibles. El segundo de los planteamientos mencionados (consideración global), en el sentido tomado en consideración en el ámbito alemán, permite afirmar el desistimiento pasivo a partir de la agrupación en el mismo intento de actos (inmediatos, pero a fin de cuentas futuros) que el autor, según su propia representación del hecho ("nach seiner Vorstellung der Tat”, \$22 StGB) al ejecutar el último de los efectuados, podría haber llevado a cabo sin interrupción espacio temporal relevante, y ello por el hecho de que se abstuvo de realizarlos. Sin embargo en nuestro derecho resulta preferible manejar un concepto objetivo de tentativa terminada, procediendo en su caso a la consideración conjunta pero solo de lo ya efectivamente realizado, con carácter únicamente retrospectivo (y no prospectivo), sin ninguna servidumbre respecto de la representación que tuviese el autor en torno a la posibilidad de consumar el hecho con los mismos o similares medios a su alcance cuando decidió abstenerse de continuar la ejecución.

5. En efecto, en nuestro derecho la solución parece que pasa por distinguir con claridad dos escenarios en función de lo dicho (terminación de la tentativa), en lugar de someter indiscriminadamente los supuestos que integran ambas situaciones al veredicto de las teorías en liza mencionadas. Así, por una parte deben contemplarse las constelaciones de casos en los que el recorrido del riesgo creado, habiendo ostentado capacidad plena ex ante de producir el resultado, ha llegado a su fin, esto es, se ha agotado objetivamente (p. ej., la explosión no ha alcanzado a la víctima; el disparo efectuado no le ha dado). Se trata aquí de tentativas terminadas, que no admiten el desistimiento. Por otra, deben abordarse los casos, distintos, en los que el peligro continúa latente, activo, que sí están en condiciones de admitir aún la impunidad subrogando en el lugar de la pena una acción de evitación cualificada. Pues bien: 
a) Solo en el primer grupo (tentativas terminadas) puede concederse alguna operatividad a la consideración global del suceso, si así quiere seguir denominándose, pues la expresión debe necesariamente entenderse adaptada al contexto de una conceptuación legal objetiva del intento punible $^{72}$. En cambio, debe prescindirse de proyectar dicha

72 El código penal español responde a una concepción esencialmente objetiva del hecho punible que parte de la lesión de bienes jurídicos como prototipo del delito (entre otros, ALCÁCER GUIRAO, R., La tentativa inidónea. Fundamento de punición y configuración del injusto, Comares, Granada, 2000, p. 477). En tal esquema encaja tanto la atenuación obligatoria (y no facultativa) prevista en el art. 62 CP como la propia definición legal de la tentativa, que alude literalmente a la realización de "todos o parte de los actos que objetivamente deberían producir el resultado". En todo caso, dejando a un lado las disputas que la nueva regulación pudo generar en su momento -en tanto que tomaba partido por una determinada concepción en torno a la fundamentación de lo injusto- y las lecturas adaptativas que pudieron hacerse para intentar ajustar la redacción a posicionamientos concretos, resulta claro que el contenido del intento punible no viene determinado en nuestro Derecho por la representación del autor.

En coherencia con ello, generalmente la doctrina española, aunque nominalmente lo califique como criterio mixto (objetivo-subjetivo), maneja en realidad un concepto objetivo para trazar la distinción entre tentativas inacabadas y acabadas. Tal criterio, enunciado en los años ochenta y asumido por monografistas de referencia en el estudio del delito intentado, implica atender al punto de vista de un espectador objetivo ex ante, aunque tomando en cuenta el plan del autor (FARRÉ TREPAT, E. La tentativa de delito. Doctrina y jurisprudencia, 1986, p. 260 y 273; 2a ed., 2011, p. 314 y 330; ALCÁCER GUIRAO, R. La tentativa inidónea ..., cit., p. 488. Un planteamiento subjetivo es, en cambio, el acogido por BACIGALUPO, siguiendo los dictados de la doctrina alemana del plan del autor-Principios de Derecho penal. PG. Akal, Madrid, $4^{\mathrm{a}}$ ed, 1997, p. 348-). Aquel último matiz (la atención al plan del autor), de carácter aparentemente subjetivo, es el que le vale al criterio el calificativo conjunto de solución mixta. Pero se trata, a la postre y como decía, de un criterio esencialmente objetivo, en la medida en que en él la referencia al plan del autor se relega a mero parámetro de interpretación del sentido (objetivo) de la conducta, sin convertir en ningún caso la representación del agente en factor dirimente del carácter inacabado o acabado del intento, ni capacitarla para convertir lo que se inicia como acabado en inacabado o viceversa (ROXIN, C., $P G, \S 30 / 163,164)$ en 
consideración global (o - para no prejuzgar aún la cuestiónla dicotomía entre la consideración global y la individual) en los segundos. Pues el criterio indicado debe utilizarse solo con carácter retrospectivo, esto es, para determinar qué hechos formaron parte de lo que ya sucedió, integrando así, en su caso, el único intento que será objeto de valoración para el desistimiento; pero no debe usarse, en cambio, para agrupar lo sucedido, con carácter prospectivo, con otros actos hipotéticos o futuros que aunque podrían haber tenido lugar sin interrupción espacio-temporal relevante, no lo tuvieron, y deducir de ello que se desistió (porque no se llevó a cabo lo sucesivo). Tomando como telón de fondo uno de los ejemplos habituales en este campo: si "A" dispone de seis balas en su cargador, y dispara dos contra su víctima de forma consecutiva ( $\sin$ cesura espacio-temporal y sin modificar el medio de ejecución), pero no alcanza con ninguna de ellas el blanco, la consideración global adaptada -si quiere, insisto, mantenerse esta denominación- nos dirá (debería decirnos) que se está ante una única tentativa, aunque externamente venga conformada por dos actos, dos fotogramas de un mismo suceso, que aisladamente considerados serían ya tenidos ex ante como suficientes para desencadenar el resultado (potencialidad lesiva plena). (Puesto que el peligro inherente a ese objeto de valoración se ha agotado -añado-no hay lugar a desistir de él -tentativa terminada-). En cambio, la teoría de la consideración global adaptada no nos dice (no debería decirnos) que, puesto que el autor disponía aún de cuatro disparos que podría haber efectuado sin cesura espacio-tem-

función de la convicción que pueda albergar el autor, en el momento de abstenerse de continuar ejecutando, acerca de si se llegará a producir o no el resultado. (En el derecho alemán, en cambio, habría tentativa inacabada en función de este criterio cuando el sujeto, en el momento en que desiste de continuar con el hecho, parte de que el resultado no se va a producir. En cambio, si el sujeto, en ese momento, no sabe si con lo hecho hasta entonces se va a producir o no el resultado y, por tanto, cuenta con ambas posibilidades, la tentativa sería acabada-ROXIN, C., $P G, \S 30 / 163,166-)$. 
poral y, sin embargo, voluntariamente no efectuó, habría desistido del homicidio ${ }^{73}$. Y lo mismo cabe afirmar, con mayor razón si cabe, en los casos en los que se renuncia a una segunda oportunidad o a una ocasión futura.

En esta materia parece residir, pues, una confusión alentada porque el uso de estas teorías en su país de origen tiene la mirada permanentemente puesta en la representación del autor (elemento requerido por el $\$ 22 \mathrm{StGB}$ ), que opera en último término como criterio aglutinante de los actos que pueden conformar una misma tentativa y, por lo tanto, la unidad valorativa a efectos del desistimiento. En cambio, con la legislación española, de corte objetivo, no es relevante si el autor tras el último acto realizado considera aún posible alcanzar el resultado sin cesura espacio-temporal ni modal destacable ${ }^{74}$. Lo importante es que el riesgo inherente a lo realizado, siendo ya suficiente ex ante para ocasionar el resul$\operatorname{tado}^{75}$, se haya agotado, tornando lo sucedido en indesistible,

73 En Memento, cit., marg. 2817, propone MOLINA para estos supuestos de desistimiento impropio omisivo de realizar nuevos actos que podrían llevar todavía a la consumación la aplicación de la atenuante de reparación, que podría operar como muy cualificada o, excepcionalmente, la exención del art. 16.2 CP por analogía.

74 Sobre el concepto objetivo (nominalmente mixto) de tentativa acabada manejado en general en la doctrina española, supra, nota 72.

75 La precisión es importante, por cuanto recuerda que las convencionalmente denominadas tentativas inacabadas no pueden constituir tentativas terminadas, si bien ello no debe inducir al error de considerar que son sin excepción desistibles. Intento aclarar a continuación estas dos consideraciones:

a) En los supuestos en los que el riesgo generado conlleva el inicio de ejecución (tentativa), pero éste no tiene todavía entidad ni autonomía suficiente para desembocar en el resultado (tentativa inacabada), el cese en la repetición sí constituye desistimiento, al no haberse agotado un riesgo suficiente para provocarlo (terminación de la tentativa) puesto que en puridad no ha existido tal riesgo hasta ese nivel. Si el autor, por ejemplo, empieza a matar a bastonazos a su víctima, propinándole indiscriminadamente varios golpes en diversas partes del cuerpo, pero decide detenerse, la no continuación (repetición de golpes) sí constituye desistimiento. Igual sucede en supuestos de estrangulamiento, con la 


\section{aunque en la contemplación de lo ya ocurrido puedan va- lorarse conjuntamente, como uno solo y por su conexión,}

simple diferencia de que en estos casos la separación de actos no es externamente perceptible. Sin embargo, si el primer golpe es ya adecuado ex ante para ocasionar por sí solo el resultado (p.e., un golpe certero en la sien, con la víctima inmovilizada, propinado con una pesada barra de hierro), el fallo en ese primer intento no convierte en desistimiento la abstención del segundo; se está ante una tentativa acabada (esto es secundario), pero además (y esto es lo decisivo) terminada, no desistible. Esa debió ser, a mi juicio, la solución aplicada a los hechos que motivaron la STS 671/2017, de 11 de octubre (Pte.: Varela Castro), en la que "el acusado pasó una cuerda alrededor del cuello a su esposa, apretándola con la intención de estrangularla y así acabar con su vida, y la ató a un gancho de la lámpara del techo de la habitación, lámpara que cayó al suelo". "Debido a la presión ejercida en el cuello con la cuerda por parte del acusado -señalan los hechos probados-, la víctima perdió el conocimiento, quedando por ello a merced del acusado, quien, no obstante y pese a su intención inicial de acabar con la vida de su esposa, de forma voluntaria, al no existir impedimento para ello, ninguna actuación realizó al efecto", circunstancia que valora el Tribunal -desacertadamente según intento exponer-como constitutiva de desistimiento. En realidad, una vez afirmada la idoneidad del intento (si efectivamente ex ante cabía concluir que la lámpara era adecuada para soportar el peso), se está ante un episodio que ha agotado la peligrosidad que le era inherente, y por tanto ante una tentativa terminada, no desistible (no fue el acusado quien descolgó a la víctima mientras se asfixiaba, sino que la lámpara que la sujetaba cayó al suelo), y ello sin perjuicio de que la eventual inidoneidad relativa del medio, o las atenciones posteriores que la víctima recibió de su agresor puedan influir en la entidad de la pena. *La sentencia indicada tiene particular interés, en otro orden de consideraciones, porque pone en cuestión la correspondencia entre la clasificación previa de la tentativa (inacabada/acabada) y la forma del desistimiento, que podría ser pasiva en una tentativa acabada.

b) De todo lo anterior no cabe deducir como axioma, sin embargo, que las tentativas inacabadas deban considerarse siempre desistibles. Aunque el peligro generado no resulte aún suficiente para producir el resultado, su progresión puede interrumpirse también de forma definitiva (inidoneidad sobrevenida del medio de ejecución, detención del autor durante la ejecución, etc.), impidiendo el desistimiento. Por lo tanto, a la distinción entre tentativas inacabadas y acabadas no puede atribuírsele tampoco esa función negativa, en el sentido de que si bien la clasificación no sería capaz de indicar positivamente dónde cabe el desistimiento, sí sería capaz de discriminar, al menos, un ámbito (tentativas inacabadas) en el que no cabría negarlo (GILI PASCUAL, A., "Pérdida de control ..., cit., n. 111). 
diferentes actos por sí solos suficientes. Esta opción consistente en agrupar actos diferentes como un único objeto de valoración a efectos del desistimiento debe, pues, preferirse a su contemplación aislada, lo que supondría considerar cada acto suficiente como una tentativa indesistible. $\mathrm{Si}$, en nuestro anterior ejemplo, se dispara de forma consecutiva, sin acertar, dos veces sobre la víctima, se estará ante una única tentativa, igual que si se hubiese disparado una sola vez, sin perjuicio de que ello pueda ser tenido en cuenta en la determinación de la pena, a la hora de considerar la "peligrosidad inherente al intento" a la que se refiere el art. $62 \mathrm{CP}$.

Este uso solo retrospectivo de la consideración global del hecho difiere, como se ha visto, del patrocinado por la teoría del mismo nombre en Alemania. En ese país, y aunque resulte mayoritaria, no puede ocultarse tampoco que la teoría de la consideración global, en los términos en los que allí ha sido sostenida, ha recibido importantes críticas, que han puesto el foco, fundamentalmente, en la imprecisión de la que pueden adolecer los criterios aglutinantes que habitualmente se emplean, por un lado, y en su supuesto mal funcionamiento en los supuestos de dolo no intencional (indirecto y eventual), por otro ${ }^{76}$. No obstante, ambas objeciones resultan sorteables, particularmente desde una configuración legal de la tentativa de corte objetivo como la española. La imprecisión aludida, que existe, no debe considerarse sin embargo mayor ni más inhabilitante que la que se constata en otros ámbitos a la hora de valorar unitariamente lo acontecido (como ocurre en el ámbito del concurso normativo y de delitos). La valoración conforme a la lógica y la experiencia del contexto temporal, espacial y modal (no así del plan del autor) son, en ese sentido, criterios válidos para conformar la convicción del juzgador sobre la unidad del intento. Y si ello es así, también la segunda línea de crítica se debilita, al

76 Se hace eco de ellas MOLINA FERNÁNDEZ, F., "Tentativa irreversible...", cit., p. 659 ss. 
no existir necesidad de conferir a la intención (por exclusión de los anteriores criterios -espacio, tiempo, forma de ejecución-) el rol de único elemento aglutinante posible entre los diversos actos a considerar. A la vez, y por otro lado, si se manejan el criterio de la terminación objetiva del intento y la consideración del desistimiento no como un derecho igualitario -proporcional al injusto- sino como mera oportunidad excepcional, pueden relativizarse las incongruencias valorativas en relación con el desistimiento en supuestos de dolo no intencional ${ }^{77}$.

b) En el segundo grupo de casos -tentativas no terminadas-, el peligro que representa la tentativa acabada sigue latente y la problemática es otra, a la que no le resulta de aplicación la dicotomía entre las teorías de la consideración global y del acto individual, ni aun adaptadas -se sobreentiende-

77 En los supuestos combinados, en los que el autor abarca intencionalmente un resultado y solo indirecta o eventualmente otro (p. e., dispara contra su objetivo sabiendo o representándose el alto grado de probabilidad de que la bala le atraviese, alcanzando también a otra víctima), se estará ante dos tentativas terminadas (sin que la posibilidad de repetir el intento contra su primera víctima pueda abrir respecto de ese resultado la puerta a un desistimiento que se le estaría negando respecto del otro, abarcado solo con dolo indirecto o eventual). Por otra parte, la no consideración del desistimiento como un derecho (igualitario) disipa, en general, las dudas relativas a disparidades valorativas en casos en los que una conducta menos desvalorada pudiera tener más difícil desistimiento que otra más desvalorada. (En este caso, tal distorsión valorativa no se daría por el hecho de que no se pudiese desistir de una tentativa con dolo eventual y sí de una con dolo directo, encrucijada que, de todos modos, ya se ha señalado que no se da).

Por lo demás, no hay obstáculo para la consideración global objetiva de varios intentos doloso eventuales (sin contar, por tanto, con la intención como elemento aglutinante entre ellos). P.e., si el autor, con la intención de obtener una confesión, somete a sucesivas descargas eléctricas al detenido, estaremos ante una tentativa terminada tras la primera, si constituía ya un riesgo suficiente por sí sola para ocasionar la muerte. No obstante, esa tentativa (no desistible), no se convertirá en tres, por ejemplo, en caso de haber sometido a la víctima a otras dos descargas más, en unidad de suceso (proximidad espacio-temporal). 
al contexto que implica una conceptuación legal objetiva del intento punible. Con la sola intención de clarificar esta idea: cuando Gimbernat sostiene ${ }^{78}$ que una vez que la víctima ha sido mortalmente apuñalada no cabe ya desistir, por haber perdido el agente el control sobre el riesgo creado, no está optando, sin mencionarla, por la Einzelakttheorie -como a veces se ha afirmado ${ }^{79}$-; sino, simplemente, contestando a un problema distinto, cual es el de la posibilidad de desistimiento tras pérdida del control del riesgo (no el de desistencia en casos de repetición), haciéndolo, por lo demás, en sentido opuesto al aquí defendido ${ }^{80}$, esto es, restringiendo el desistimiento en las tentativas acabadas a las acabadas imperfectas.

\section{Bibliografía}

ALASTUEY DOBÓN, C.: "Tentativa inacabada, tentativa acabada y desistimiento", Revista de Derecho Penal y Criminología, 2011.

ALCÁCER GUIRAO, R.: "Tentativa y desistimiento en la comisión por omisión", La Ley, n 5, 2002.

ALCÁCER GUIRAO, R.: ¿Está bien lo que bien acaba? La imputación de la evitación del resultado en el desistimiento, Ed. Comares, Granada, 2002.

ALCÁCER GUIRAO, R.: Tentativa y formas de autoría. Sobre el comienzo de la realización típica, Ed. Edisofer, Madrid, 2001.

ALCÁCER GUIRAO, R.: "Comienzo de la tentativa en la comisión por omisión", Cuadernos de Política Criminal, $\mathrm{n}^{\mathrm{o}} 73,2001$.

78 Cuestionando lo decidido en la STS 446/2002, de 1 de marzo (Pte.: Jiménez Villarejo): GIMBERNAT ORDEIG, E., "El desistimiento ..., cit., p. 29 ss.

79 ALASTUEY DOBÓN, C., "Tentativa inacabada, tentativa acabada y desistimiento", Revista de Derecho Penal y Criminología, 2011, p. 22, n. 26.

80 Posibilidad de desistimiento en tanto subsista activo el riesgo, si se consigue desplegar una opción óptima de evitación. 
ALCÁCER GUIRAO, R.: "La reparación en Derecho penal y la atenuante del artículo $21.5^{\circ} \mathrm{CP}$. Reparación y desistimiento como actos de revocación". Revista del Poder Judicial, $3^{\mathrm{a}}$ época, $\mathrm{n}^{\circ}$ 63, 2001.

ALCÁCER GUIRAO, R.: La tentativa inidónea. Fundamento de punición y configuración del injusto, Ed. Comares, Granada, 2000.

BACIGAlUPO ZAPATER, E.: Principios de Derecho Penal. Parte General, 4a, Ed. Akal, Madrid, 1997.

BENLLOCH PETIT, G.: "De cómo el injusto de la tentativa va variando según avanza la ejecución y de cómo esto incide en la fundamentación de la impunidad por desistimiento", Rev. Peruana de Jurisprudencia, año 4, núm. 24, 2003.

DEMETRIO CRESPO, E.: La tentativa en la autoría mediata y en la actio libera in causa: una contribución al estudio del fundamento de punición y comienzo de la tentativa. Ed. Comares, Granada, 2003.

FARRÉ TREPAT, E.: La tentativa de delito. Doctrina y jurisprudencia, Bosch, Barcelona. (También, $2^{\mathrm{a}}$ ed., BdeF, Montevideo-Buenos Aires, 2011).

GARCÍA PÉREZ, O., La punibilidad en el Derecho penal, Aranzadi, Pamplona, 1997.

GILI PASCUAL, A.: "Pérdida de control sobre el riesgo creado y terminación del delito intentado", InDret 2/2012.

GILI PASCUAL, A.: Desistimiento y concurso de personas en el delito, Ed. Tirant lo Blanch, Valencia, 2009.

GIMBERNAT ORDEIG, E.: "El desistimiento en la tentativa acabada", Anuario de Derecho Penal y Ciencias Penales, 2006.

GIMBERNAT ORDEIG, E.: "Causalidad, omisión e imprudencia", Anuario de Derecho Penal y Ciencias Penales, 1994.

GIMBERNAT ORDEIG, E.: Autor y cómplice en Derecho penal. Universidad de Madrid. Facultad de Derecho. Sección de Publicaciones e Intercambio, 1966. 
HERNÁNDEZ PLASENCIA, J.U., La autoría mediata en Derecho penal. Ed. Comares, Granada, 1996.

JAKOBS, G., "La conducta de desistimiento", en Homenaje al Prof. Dr. Gonzalo Rodríguez Mourullo. Ed. Thomson-Civitas, Madrid, 2005.

MARTÍNEZ-BUJÁN PÉREZ, C.: La autoría en Derecho penal. Un estudio a la luz de la concepción significativa (y del Código penal español). Ed. Tirant lo Blanch, Valencia, 2019.

MIR PUIG, S.: Derecho penal. Parte general. $10^{\mathrm{a}}$ ed. (con la colaboración de V. GÓMEZ MARTÍN y V. VALIENTE IVÁÑEZ). Ed. Reppertor, Barcelona, 2015.

MOLINA FERNÁNDEZ, F.: Tentativa irreversible y desistimiento impropio, en CANCIO MELIÁ et alter (ed.), Libro Homenaje al Prof. Dr. A. Jorge Barreiro, vol. I, UAM, Madrid, 2019.

MOLINA FERNÁNDEZ, F.: "Formas imperfectas de ejecución del delito", en Memento práctico penal, Cap. 11, Ed. Francis Lefebvre, Madrid, 2017.

RAGUÉS VALLÈS, R.: El dolo y su prueba en el proceso penal, Ed. Bosch, Barcelona, 1999.

ROXIN, C.: Derecho penal. Parte general. Tomo II: Especiales formas de aparición del delito (trad. de la $1^{\mathrm{a}}$ ed. alemana, a cargo de LUZÓN PEÑA, dir.). Civitas, Madrid, 2014.

ROXIN, C., "Sobre el desistimiento de la tentativa inacabada", en Problemas básicos del derecho penal (trad. del original publicado en Heinitz-FS, Berlin, 1972, a cargo de D.M. Luzón). Ed. Reus, Madrid, 1976.

ROXIN, C.: "Der Anfang des beendeten Versuchs", en Festschrift für R. Maurach zum 70. Geburtstag, Müller Verlag, 1972.

SCHMIDHÄUSER, E., con la colaboración de Heiner Alwart, Strafrecht. Allgemeiner Teil (Studienbuch), J.C.B. Mohr (Paul Siebeck), Tübingen, 1984. 
SERRANO GONZÁLEZ DE MURILLO, J.L.: "¿Tentativa fracasada existiendo posibilidades de realizar aún el tipo?, Revista de Derecho Penal y Criminología, ${ }^{\circ} 16$, 2005. 